\title{
Climatological Features of the Weakly and Very Stably Stratified Nocturnal Boundary Layers. Part II: Regime Occupation and Transition Statistics and the Influence of External Drivers
}

\author{
CARSTEn Abraham AND AdAm H. Monahan \\ School of Earth and Ocean Sciences, University of Victoria, Victoria, British Columbia, Canada
}

(Manuscript received 28 March 2019, in final form 9 August 2019)

\begin{abstract}
In a companion paper hidden Markov model (HMM) analyses have been conducted to classify the nocturnal stably stratified boundary layer (SBL) into weakly stable (wSBL) and very stable (vSBL) conditions at different tower sites on the basis of long-term Reynolds-averaged mean data. The resulting HMM regime sequences allow analysis of long-term (climatological) SBL regime statistics. In particular, statistical features of very persistent wSBL and vSBL nights, in which a single regime lasts for the entire night, are contrasted with those of nights with SBL regime transitions. The occurrence of very persistent nights is seasonally dependent and more likely in homogeneous surroundings than in regions with complex terrain. When transitions occur, their timing is not seasonally dependent, but transitions are enhanced close to sunset (for land-based sites). The regime event durations depict remarkably similar distributions across all stations with peaks in transition likelihood approximately $1-2 \mathrm{~h}$ after a preceding transition. At Cabauw in the Netherlands, very persistent wSBL and vSBL nights are usually accompanied by overcast conditions with strong geostrophic winds $U_{\text {geo }}$ or clear-sky conditions with weak $U_{\text {geo }}$, respectively. In contrast, SBL regime transitions can neither be linked to magnitudes in $U_{\text {geo }}$ and cloud coverage nor to specific tendencies in $U_{\text {geo }}$. However, regime transitions can be initiated by changes in low-level cloud cover.
\end{abstract}

\section{Introduction}

The nocturnal stably stratified boundary layer (SBL) is often classified into two distinct regimes with very different physical structures: the weakly stable boundary layer (wSBL) and the very stable boundary layer (vSBL). These regimes differ in stratification, flow profile, and turbulence intensity (e.g., Mahrt 1998a; Acevedo and Fitzjarrald 2003; Mahrt 2014; van Hooijdonk et al. 2015; Monahan et al. 2015; Vercauteren and Klein 2015; Acevedo et al. 2016; Vignon et al. 2017b; Abraham and Monahan 2019a,b, hereafter AM19a and AM19b). This study uses data from several tower sites in different meteorological settings to investigate the long-term occupation and transition statistics of SBL regimes. Furthermore, the relationship between external drivers and regime occupation and regime transitions are assessed. While this two-regime classification is the simplest among those that have been proposed for the SBL, we have demonstrated that it provides the most robust distinction in

\footnotetext{
Corresponding author: Carsten Abraham, abrahamc@uvic.ca
}

terms of Reynolds-averaged state variables for which sufficiently long time series are available to develop long-term statistics or climatologies (AM19a). We use the term "climatological" in this context to refer to the characterization of statistics from many years of observations.

In this two-regime classification the wSBL describes a regime of weakly stable stratification, often found under cloudy or overcast conditions or moderate to strong winds. For sufficiently strong wind conditions, large shears produce enough turbulence kinetic energy (TKE) to sustain vertical turbulent mixing despite stable stratification (e.g., van de Wiel et al. 2012a). The vertical turbulent heat fluxes in turn are sufficient to compensate energy losses at the surface sustaining weakly stable temperature profiles. This regime conforms to the classical understanding of turbulence in the atmospheric boundary layer with turbulent quantities decreasing with height and near-surface profiles, which are well described by Monin-Obukhov similarity theory (MOST) in horizontally homogeneous conditions, resulting in continuous turbulence intensities (e.g., Sorbjan 1986; 
Mahrt 1998a,b, 2014; Pahlow et al. 2001; Grachev et al. 2005, 2013).

There are two main mechanisms by which a wSBL cannot be sustained and transitions to the vSBL are initiated: horizontal advection of warm air over a cold surface, and net surface radiative energy loss (e.g., AM19b). The latter dominates formation of the nocturnal SBL. During the nighttime transition, the net radiative energy flux at the surface changes sign and the atmospheric layers near the surface begin to cool. If winds are sufficiently weak, TKE production and turbulent fluxes weaken to the point of near turbulence collapse and the atmospheric layers decouple from each other. The decrease in vertical turbulent heat fluxes leads to strong radiative cooling such that a very stable temperature profile is produced and the vSBL is established. This process is often too strong in models, with runaway cooling resulting in unrealistically strong inversions (e.g., Mahrt 1998b; Walsh et al. 2008).

The vSBL is associated with strong statically stable stratification, often under clear-sky conditions or relatively weak winds, with turbulence profiles, which can be decoupled from the surface (Banta et al. 2007); turbulence intensities, which can increase with height; or highly anisotropic turbulent motions (Mauritsen and Svensson 2007). The resulting turbulence is not continuous and MOST does not hold (e.g., Derbyshire 1999; Banta et al. 2007; Williams et al. 2013; Mahrt 2011; Optis et al. 2016). In particular, turbulence does not scale with the mean boundary layer state in the vSBL (Sun et al. 2012). The result is that measured turbulence in the vSBL is usually characterized by intermittent turbulence events without an evident deterministic relationship with the mean state (Rees and Mobbs 1988; Lang et al. 2018).

Intermittent turbulence arises from a range of different phenomena such as breaking gravity waves or solitary waves (Mauritsen and Svensson 2007; Sun et al. 2012), density currents (Sun et al. 2002), microfronts (Mahrt 2010), Kelvin-Helmholtz instabilities interacting with the turbulent mixing (Blumen et al. 2001; Newsom and Banta 2003; Sun et al. 2012), or shear instabilities induced from internal wave propagation (Sun et al. 2004; Zilitinkevich et al. 2008; Sun et al. 2015). Many of these intermittent events can be associated with turbulence values that are sufficient to initiate regime transitions from the vSBL back to the wSBL (e.g., Sun et al. 2002, 2004, 2012).

The existence of the two-regime SBL structure can be understood in terms of the conceptual framework of the maximum sustainable downward heat flux (MSHF; van de Wiel et al. 2007, 2012a,b, 2017; van Hooijdonk et al.
2015). The MSHF is determined by two competing factors: the strength of the temperature gradient and the intensity of vertical mixing (de Bruin 1994; Malhi 1995; van Hooijdonk et al. 2015; van de Wiel et al. 2017). In stably stratified conditions, turbulent fluxes are local and described well by flux-gradient relationships. Nearneutral temperature profiles therefore result in a small heat flux. Similarly, under very stable conditions turbulent fluxes are suppressed due to the strong density gradients and the turbulent sensible heat flux is weak. Between these two limiting cases, a flow-dependent maximum turbulent heat flux exists. If the MSHF is less than the turbulent heat flux needed to balance energy losses at the surface the turbulence collapses and the vSBL is established. Otherwise, a wSBL is established. According to this framework the transition between the two regimes is expected to occur at a transition wind speed determined by the local surface roughness and air-surface energetic coupling (van de Wiel et al. 2017).

Even though the MSHF framework is conceptually valuable, observations show that the two regimes are not separated by a clear wind speed threshold (e.g., Monahan et al. 2015; AM19a). One reason is that not only local characteristics but also external drivers modulate the energetics of the near-surface flow. External drivers such as pressure gradient force and cloud coverage have been found in several studies to have an important impact on occupation statistics of the regimes (Nieuwstadt 1984; Poulos et al. 2002; van de Wiel et al. 2002, 2012a; Edwards 2009; Svensson et al. 2011; Monahan et al. 2015).

Although SBL regimes have been extensively studied in recent years, these regimes and transitions between them are not represented well in weather and climate models, due to both coarse resolution (vertical and horizontal) and imperfect understanding and representation of the diverse subgrid-scale physics governing the SBL (e.g., Holtslag et al. 2013; Mahrt 2014). The result is substantial errors of SBL representation in these models (Dethloff et al. 2001; Gerbig et al. 2008; Bechtold et al. 2008; Medeiros et al. 2011; Kyselý and Plavcová 2012; Tastula et al. 2012; Sterk et al. 2013; Bosveld et al. 2014; Sterk et al. 2015). Misrepresentation of the SBL includes unrealistic decoupling of the atmosphere from the surface resulting in runaway surface cooling (Mahrt 1998b; Walsh et al. 2008), underestimation of the wind turning with height within the boundary layer (Svensson and Holtslag 2009), overestimation of the boundary layer height (Bosveld et al. 2014), underestimated low-leveljet speed (Baas et al. 2009), and underestimation of near-surface wind speed and temperature gradients or their diurnal cycle (Edwards et al. 2011). 
Global and regional weather and climate models often use an artificially enhanced turbulent activity under stable conditions in order to improve simulations of the large-scale flow (Holtslag et al. 2013). This approach has led to the introduction of long-tailed stability functions not justifiable by observations. In such models, turbulence is artificially sustained under very stable conditions and the two-regime characteristic of the SBL is suppressed, consistent with the biases mentioned above. Although the long-tailed stability functions in relatively coarse-resolution models mimic to some extent the effect of subgrid-scale regime variation, with increasing horizontal and vertical resolution more accurate process-based parameterizations are necessary. As the vSBL-to-wSBL transition in particular can be associated with intermittent turbulence events (many of which result from subgrid-scale phenomena), weather and climate models may be required to account for SBL regime dynamics explicitly stochastically (e.g., He et al. 2012; Mahrt 2014). Supporting the idea of representing intermittent turbulence events by stochastic parameterizations is the fact that their structure and propagation are found to depend only weakly on the mean states (e.g., Rees and Mobbs 1988; Lang et al. 2018). Such stochastic subgrid-scale parameterizations have the potential to improve biases of climate mean states and forecast ensemble spread (e.g., He et al. 2012; Mahrt 2014; Nappo et al. 2014; Vercauteren and Klein 2015). The development of such a class of parameterizations requires long-term statistics of SBL regimes. Furthermore, these regimes are a fundamental aspect of the variability of the SBL. As such, long-term characterizations of regime occupation and transition statistics are of general utility for questions regarding SBL processes. In AM19a we established that a hidden Markov model (HMM) analysis of the three-dimensional statevariable space of Reynolds-averaged vertical mean wind speed, wind speed shear, and stratification clusters longterm observational tower data systematically into wSBL and vSBL regimes.

The HMM is a statistical model that determines an unobserved (therefore "hidden") Markov chain sequence on the basis of a set of observed state variables (Rabiner 1989). The HMM associates each observation with a discrete regime corresponding to a (hidden regime dependent) parametric probability density function (pdf). In the case of the SBL the number of predefined regimes is chosen to be two, based on visual inspection of the data scatter and the fact that HMM analyses of these data using more than two hidden regimes showed no robust structures across different tower sites (AM19a). As is discussed in detail in AM19a, the two-regime classification we consider is the simplest of the various SBL classification schemes that have been proposed (e.g., Acevedo and Fitzjarrald 2003; Acevedo et al. 2016; Grachev et al. 2005, 2008; Sun et al. 2012; van de Wiel et al. 2012a,b, 2017; Mahrt 2014; Ansorge and Mellado 2014; Vercauteren and Klein 2015; Monahan et al. 2015; AM19a). Most classification schemes involving more than two regimes are based on the details of the turbulent and submesoscale variability of the flow, and are therefore not distinguished by the long-term Reynolds-averaged data we consider. Details of the application of the HMM to the tower data considered in this study are presented in AM19a.

The HMM-based allocation of the data to the wSBL and $\mathrm{VSBL}$ regimes was shown in AM19a to be effective and to describe similar structures at nine different tower sites, allowing for a systematic assessment of long-term (climatological) regime occupation and transition statistics as needed for parameterizations of the effects of SBL regime dynamics. From the regime occupation sequence a distinction can be made between nights in which transitions occur and "very persistent" nights without any regime transitions. As will be discussed in this study the occurrence of both types of nights is a common feature at all tower sites considered. We will demonstrate that these two classes of night are distinguished by differences in seasonal variations of occurrence frequency and in their relationships to synoptic meteorological conditions (geostrophic wind and lowlevel cloud cover). In this study, we investigate the long-term occupation and transition statistics of this two-regime SBL classification with a particular attention to the contrast between nights with and without regime transitions. In the companion paper AM19b we concentrate on composite structures of atmospheric state variables in very persistent nights and their changes at times of SBL regime transitions.

This study is organized as follows. First, a brief review of the data used to obtain the HMM regime occupation time series is presented (section 2), followed by results and conclusions in sections 3 and 4, respectively.

\section{Data}

We consider observational datasets from nine different research towers measuring standard Reynolds-averaged meteorological state variables with a time resolution of $30 \mathrm{~min}$ or finer (Table 1). We use the same data discussed in detail in AM19a, which is why only a short summary of the data follows.

The reference state-variable spaces for each set of tower data that are used in the HMM analyses (consisting of stratification and wind speeds at two levels) are identified in Table 1 . These reference sets were obtained 


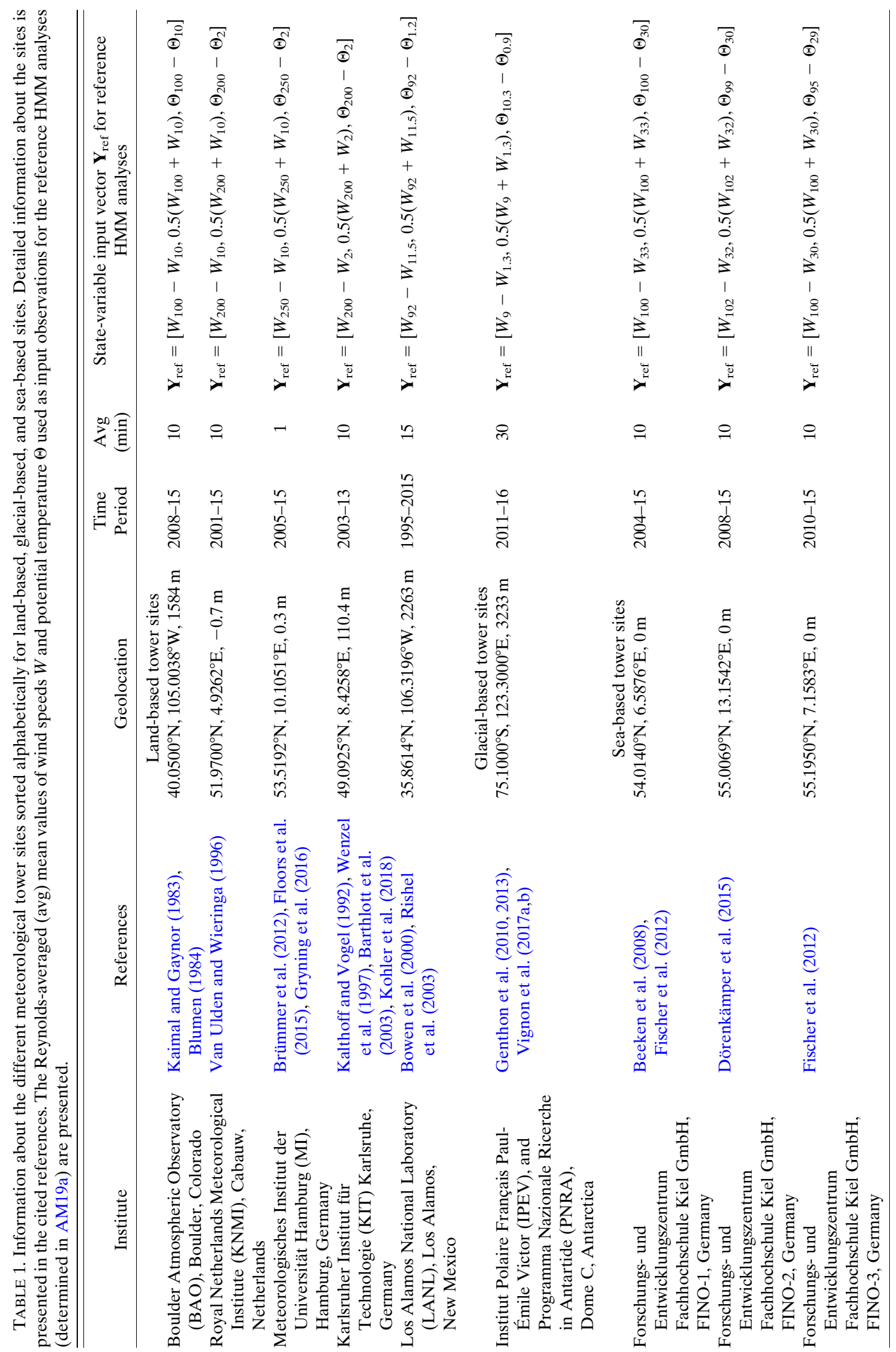


TABLE 2. Percentages of very persistent wSBL and vSBL nights and nights experiencing turbulence collapse (wSBL-to-vSBL transition) and turbulence recovery events (vSBL-to-wSBL transitions) as classified by the regime sequences estimated from HMM on the statevariable set indicated in Table 1 at each tower site and climatological distributions of starting a night in the wSBL ( $\left.\pi_{\mathrm{wSBL}}\right)$ or vSBL $\left(\pi_{\mathrm{vSBL}}\right)$.

\begin{tabular}{|c|c|c|c|c|c|c|}
\hline Tower site & wSBL nights & vSBL nights & wSBL to vSBL & vSBL to wSBL & $\pi_{\mathrm{wSBL}}$ & $\pi_{\mathrm{vSBL}}$ \\
\hline \multicolumn{7}{|c|}{ Land-based tower sites } \\
\hline Boulder & 4.28 & 15.44 & 75.14 & 55.42 & 55.31 & 44.69 \\
\hline Cabauw & 22.17 & 27.86 & 42.03 & 24.47 & 61.37 & 38.63 \\
\hline Hamburg & 29.64 & 8.30 & 58.49 & 30.14 & 84.99 & 15.01 \\
\hline Karlsruhe & 22.18 & 25.47 & 41.34 & 25.38 & 65.25 & 34.75 \\
\hline Los Alamos & 12.51 & 11.81 & 71.32 & 35.91 & 77.75 & 22.25 \\
\hline \multicolumn{7}{|c|}{ Sea-based tower sites } \\
\hline FINO-1 & 55.45 & 15.89 & 16.36 & 21.50 & 67.76 & 32.24 \\
\hline FINO-2 & 38.26 & 31.22 & 15.89 & 25.64 & 51.84 & 48.16 \\
\hline FINO-3 & 52.06 & 23.28 & 16.03 & 17.40 & 66.56 & 33.44 \\
\hline
\end{tabular}

in AM19a as the smallest state-variable sets that resulted in robust wSBL and vSBL regime occupation sequences at each location. The Reynolds-mean wind speed data at two altitudes provide information about scalar shear near the surface and aloft. Together with the stratification, these data describe the competing mechanisms of TKE shear production and buoyancy consumption, and are natural state variables to distinguish the two regimes.

Substantial differences among the nine experimental sites exist in terms of their surface conditions, surrounding topography, and meteorological setting. As a simple classification scheme, we distinguish between land-based, glacial-based, and sea-based stations. The land-based stations can be further clustered into different subsets. Both the Cabauw and Hamburg towers lie in flat, moist, grassland areas, although the Hamburg tower is affected by the large metropolitan area of Hamburg. The Karlsruhe tower is located in the Rhine valley, a rather hilly, forested area north of the Karlsruhe urban area and due to the local flow patterns often in the lee of the city. The American sites, Boulder and Los Alamos, are strongly affected by the surrounding topography of the Rocky Mountains and are located in much more arid areas than the other land-based stations.

The Dome C observatory, the single glacial-based station, is located in the interior of Antarctica and influenced by completely different surface conditions including high albedo and low roughness length.

The sea-based stations are the offshore research platforms Forschungsplattform in Nord- und Ostsee (FINO), which are located in the North Sea (FINO-1 and FINO-3) and Baltic Sea (FINO-2). These sites are characterized by relatively homogeneous local surroundings and a large surface heat capacity. At the FINO towers we exclude nights with statically unstable conditions (defined as nights with two or more unstable data points in a night) as under these conditions wind speed measurements have been found to be unreliable (Westerhellweg and Neumann 2012). Furthermore, at FINO-1 nights with primary wind directions between $280^{\circ}$ and $340^{\circ}$ are excluded due to mast interference effects. At the other stations such an exclusion is not necessary as three wind measurements with $120^{\circ}$ separation are taken at each level.

At those sites where the data are available to do so, we define the beginning of the night as the time the net radiative surface flux $Q_{N}$ [sum of downwelling and upwelling longwave radiation (LWR) and shortwave radiation (SWR)] becomes negative. By this definition, the beginning of the night can be earlier than the actual sunset or the time that SWR becomes zero. The full suite of radiation flux data are only available at Cabauw, Hamburg, and Los Alamos. At observational sites where radiative fluxes are not available, we define the night as starting $2 \mathrm{~h}$ before actual sunset given by the date and geographical location.

Static stabilities are calculated as the potential temperature $(\Theta)$ difference between two heights. Potential temperatures are calculated assuming hydrostatic equilibrium, an acceleration due to gravity of $9.81 \mathrm{~m} \mathrm{~s}^{-2}$, a specific heat capacity of $1005 \mathrm{~J} \mathrm{~kg}^{-1} \mathrm{~K}^{-1}$, and the specific gas constant of $287 \mathrm{~J} \mathrm{~kg}^{-1} \mathrm{~K}^{-1}$.

Information about the percentage of cloud cover at Cabauw is obtained from ceilometer measurements provided from 1 July 2007 to 31 December 2015. At this site, we have calculated estimates of geostrophic vector winds from hourly surface pressure $\left(P_{s}\right)$ measurements from 34 meteorological stations of the Royal Netherlands Meteorological Institute (KNMI) within $80 \mathrm{~km}$ of Cabauw for the same time period as the measurements of the Cabauw tower observations. A two-dimensional cubic spline fit (the griddata function of the scipy interpolate package) of the station data onto a $1 \mathrm{~km} \times 1 \mathrm{~km}$ grid is 

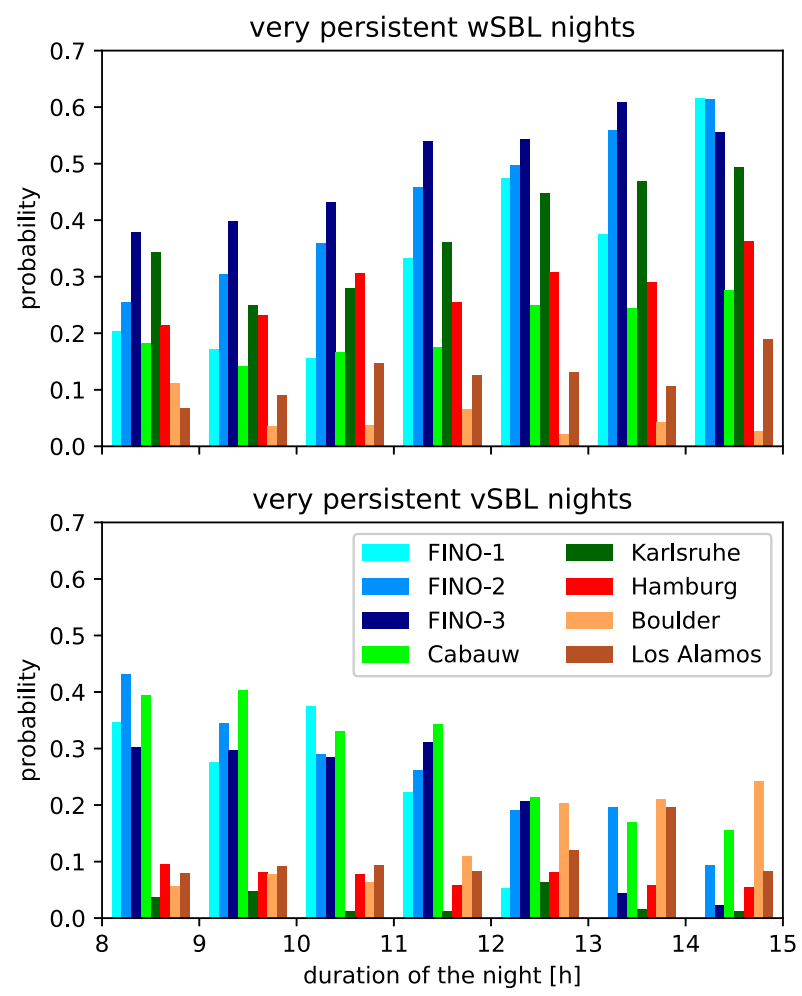

FIG. 1. Probabilities of the occurrence of very persistent (top) wSBL and (bottom) vSBL nights conditioned on the length of the night (in bins of $1 \mathrm{~h}$ ) at the different tower sites as determined by the HMM analyses using the reference state-variable sets (indicated in Table 1).

used to obtain an estimation of the pressure field. The components of the geostrophic wind are determined by the zonal and meridional derivatives of the pressure field, approximated by finite differences over a geographical degree centered at the Cabauw tower.

\section{Results}

In AM19a we used the HMM to obtain regime occupation sequences classifying nighttime data into the wSBL and vSBL at the different tower sites. Here, we use the regime occupation sequences in order to study two fundamentally different types of nights: nights without regime transitions, referred to as "very persistent" nights, and nights that experience transitions between the wSBL and vSBL. We first investigate the frequency of occurrence of these different types of nights. This part of the analysis makes use of the tower sites with the exception of the glacial-based station, Dome C in Antarctica. Because the duration of the polar nights is much longer than at the other midlatitude stations considered, differences between "very persistent" nights and nights with transitions
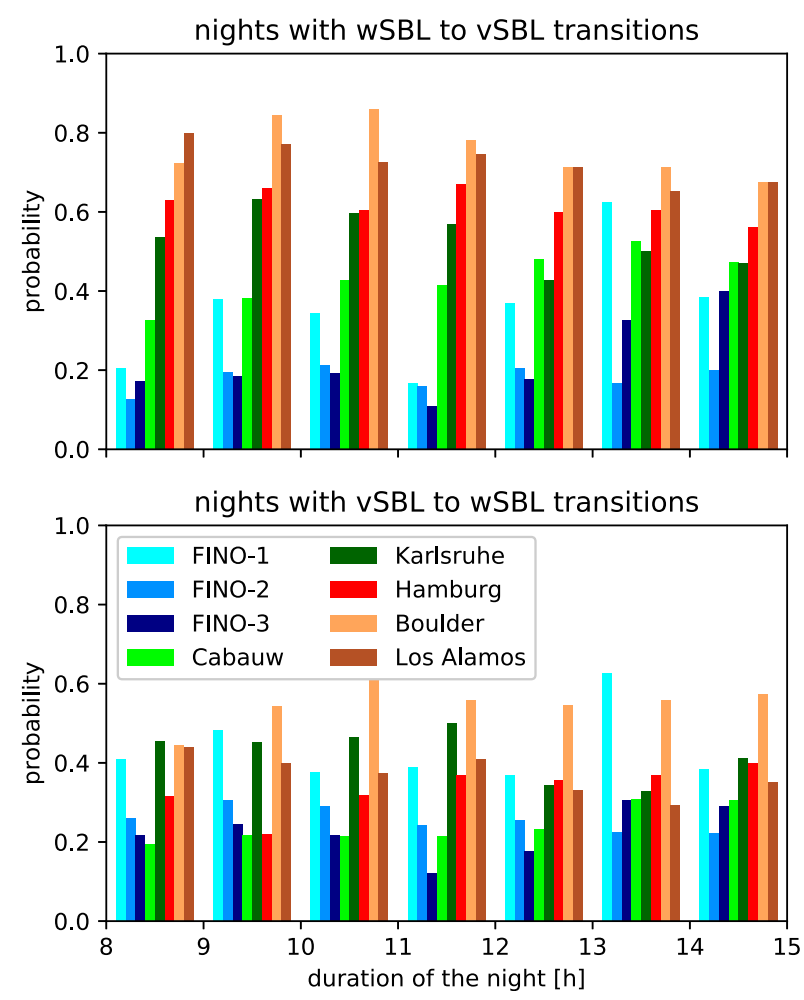

FIG. 2. As in Fig. 1, but for the occurrence probabilities of (top) wSBL-to-vSBL and (bottom) vSBL-to-wSBL transitions.

cannot be determined and direct comparisons of those regime occupation statistics to other sites are not meaningful. Focusing on nights with transitions, we then examine the evolution of the probability distribution of transition occurrences across the night as well as the distribution of regime event durations (for which we include the Dome C data). Finally, we assess the relationship between regime occupation and transition statistics and external drivers such as the geostrophic wind $U_{\text {geo }}$ and the low-level cloud coverage (LLCC). For conciseness, in the following we will refer to wSBL-to-vSBL transitions as turbulence collapse (although intermittent turbulence events are a feature of the vSBL). Similarly, we will refer to vSBL to wSBL as turbulence recovery.

\section{a. Occurrence frequencies of nights with and without transitions}

Across the land-based stations, very persistent nights are a common feature of SBL regime statistics (Table 2, columns 2 and 3). The combined occurrence probability of both types of very persistent nights range from about $20 \%$ at the relatively arid American sites to a maximum of about $50 \%$ at Cabauw, a station in a moist environment with strong influence of cloud cover (cf. section 3c). With the exception of Boulder 
TABLE 3. Percentages of nights in which turbulence recovery events occur after a previous turbulence collapse (column 2) and conditional probability of the occurrence of such turbulence recovery events (column 3 ) as classified by the HMM regime sequences. The mean and median times between the turbulence collapse and subsequent turbulence recovery events are stated in columns 4 and 5 , respectively. Percentages of nights in which turbulence collapse events occur after a previous turbulence recovery (column 6) and the conditional occurrence probability of such turbulence collapse events (column 7) as classified by the HMM regime sequences. The mean and median times between the turbulence recovery and subsequent turbulence collapse events are stated in columns 8 and 9 , respectively.

\begin{tabular}{|c|c|c|c|c|c|c|c|c|}
\hline \multirow[b]{2}{*}{ Tower site } & \multicolumn{4}{|c|}{ Subsequent recovery events } & \multicolumn{4}{|c|}{ Subsequent collapse events } \\
\hline & $\begin{array}{c}\text { Nights with } \\
\text { occurrence (\%) }\end{array}$ & $\begin{array}{c}\text { Subsequent } \\
\text { recovery }(\%)\end{array}$ & $\begin{array}{c}\text { Mean } \\
\text { time }(\mathrm{h})\end{array}$ & $\begin{array}{l}\text { Median } \\
\text { time (h) }\end{array}$ & $\begin{array}{c}\text { Nights with } \\
\text { occurrence (\%) }\end{array}$ & $\begin{array}{c}\text { Subsequent } \\
\text { collapse (\%) }\end{array}$ & $\begin{array}{c}\text { Mean } \\
\text { time }(\mathrm{h})\end{array}$ & $\begin{array}{l}\text { Median } \\
\text { time (h) }\end{array}$ \\
\hline \multicolumn{9}{|c|}{ Land-based tower sites } \\
\hline Boulder & 37.22 & 49.53 & 3.1 & 2.5 & 39.56 & 71.38 & 2.7 & 2.2 \\
\hline Cabauw & 15.90 & 37.84 & 3.9 & 3.0 & 9.17 & 37.46 & 3.2 & 2.5 \\
\hline Hamburg & 29.05 & 49.66 & 3.4 & 2.5 & 16.16 & 53.63 & 2.3 & 1.7 \\
\hline Karlsruhe & 16.97 & 41.06 & 4.1 & 3.0 & 7.66 & 30.20 & 3.2 & 2.3 \\
\hline Los Alamos & 25.66 & 35.98 & 3.5 & 2.7 & 21.57 & 60.08 & 2.9 & 2.3 \\
\hline \multicolumn{9}{|c|}{ Sea-based tower sites } \\
\hline FINO-1 & 8.57 & 52.38 & 3.4 & 2.7 & 7.41 & 34.50 & 2.7 & 2.4 \\
\hline FINO-2 & 9.96 & 62.71 & 2.9 & 2.2 & 7.77 & 30.31 & 2.6 & 2.0 \\
\hline FINO-3 & 4.99 & 31.11 & 3.8 & 2.8 & 10.02 & 57.59 & 3.1 & 2.3 \\
\hline
\end{tabular}

and Hamburg, both types of very persistent nights are approximately equally likely. The different frequencies of very persistent nights at those two stations might reflect different characteristics of the local environment. The much higher probability of very persistent vSBL nights at Boulder than wSBL nights can be related to the fact that in the lee of the Rocky mountains, periods of large-scale subsidence and relatively low cloud coverage are relatively common. The elevated probability of very persistent wSBL in comparison to vSBL nights at Hamburg might be related to the influence of the nearby city. The tower is more often downwind of the city than upwind, and we find that all very persistent vSBL nights are observed for times when the tower is upwind of the city (not shown).

Frequencies of very persistent nights at seabased towers are generally larger than those on land. At FINO-2 (located in the Baltic sea) the occurrence of very persistent wSBL nights is considerably lower than at the sites in the North Sea where about half of the nights experience such conditions. Very persistent vSBL nights, on the other hand, are more probable at FINO-2 than at the other sites. The higher likelihood of very persistent SBL conditions at these sea-based sites is consistent with the controlling influence of the presence or absence of warm air advection aloft, which dominates regime occupation statistics at these locations (AM19b). This advection is expected to be often associated with synoptic-scale processes, and therefore relatively slowly evolving with time. More frequent very persistent vSBL nights at FINO-2 may result from the fact that of all the sea-based towers
FINO-2 is the most influenced by the advection of warm air from the nearby land, by which it is surrounded in almost all directions (Dörenkämper et al. 2015).

The occurrence of very persistent nights is found to depend strongly on the duration of the night, which evolves over the year (Fig. 1). In the midlatitudes the shortest nights are about $8 \mathrm{~h}$ (summer) and longest about $15 \mathrm{~h}$ (winter). With the exception of Boulder, the probabilities of the occurrence of very persistent wSBL nights increase with longer durations of nights (Fig. 1, top panel). Such an increase in very persistent wSBL nights in winter is consistent with the fact that in the northern midlatitudes meteorological conditions favor stronger winds than in summer months due to stronger geostrophic forcing (cf. section $3 \mathrm{c}$ ). Consistent with this picture, the occurrence of very persistent vSBL nights decreases with lengths of nights across all stations except for Boulder, where the occurrence frequency increases (Fig. 1, bottom panel). Furthermore, besides the stronger geostrophic forcing in winter, longer nights have a higher probability of experiencing intermittent turbulence events of sufficient strength to disrupt the vSBL and prevent a night from persistently occupying this regime.

Similar to very persistent nights, turbulence collapse and recovery events are also common features of the SBL (Table 2, columns 4 and 5). At land-based stations turbulence collapses occur in the majority of nights $(40 \%-75 \%)$, and are considerably rarer at the sea-based stations. The arid American sites exhibit the most frequent occurrence of wSBL-to-vSBL transitions. These locations experience less cloud 

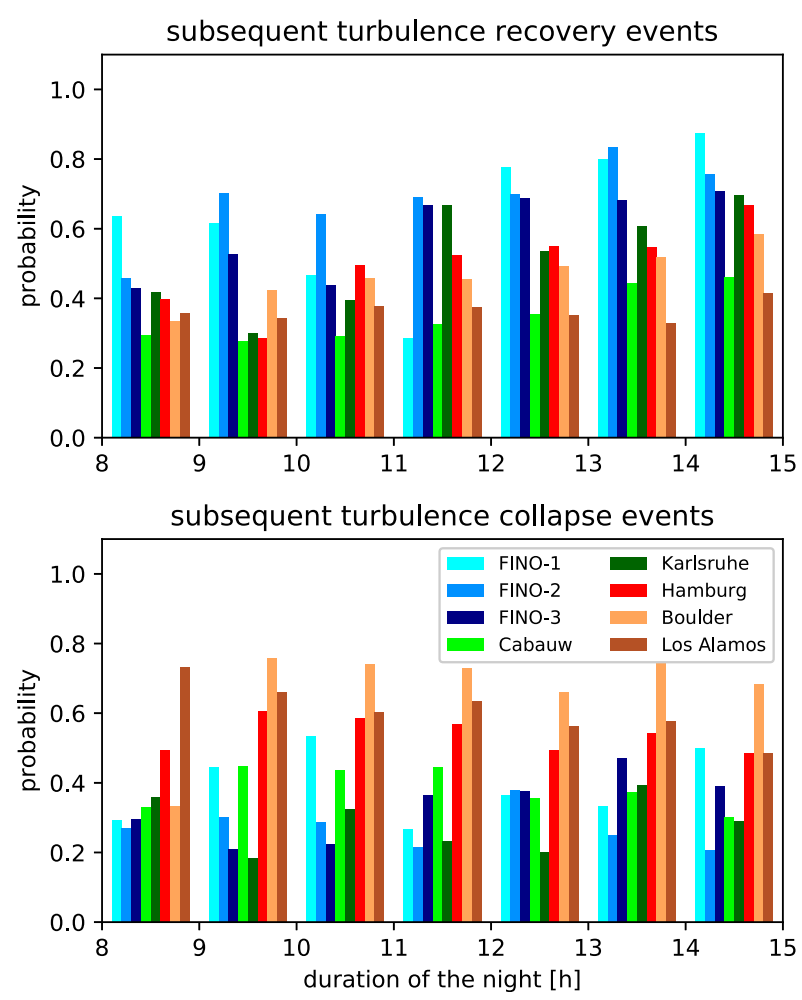

FIG. 3. As in Fig. 1, but showing the probabilities of the occurrence of (top) turbulence recovery events subsequent to turbulence collapse events and (bottom) turbulence collapse events after preceding turbulence recovery events.

cover in the climatological mean leading to a more effective radiative cooling (cf. section 3c). Furthermore, drier surfaces at these sites have lower heat capacities and lower thermal conductivities, which encourage the formation of strong inversions and turbulence collapse (van de Wiel et al. 2017). The other land-based sites are located in humid environments with more frequent low-level cloud cover. The sea-based stations show fewer turbulence collapses than any of the land-based stations, likely because transitions are exclusively caused by advection of warm air aloft (AM19b), which requires that the flow be aligned against the temperature gradient.

Occurrence probabilities of turbulence recovery events within a night have about the same probability $(20 \%-$ $30 \%$ ) at stations other than Boulder and Los Alamos, where the occurrence is much more frequent. This difference might simply be caused by the higher frequency of turbulence collapse episodes at these locations allowing for the possibility of more vSBL-to-wSBL transitions. Furthermore, these two stations are located in regions where mountain processes lead to a higher probability of intermittent turbulence events to occur, which can initiate a wSBL-to-vSBL transition (cf. AM19a).
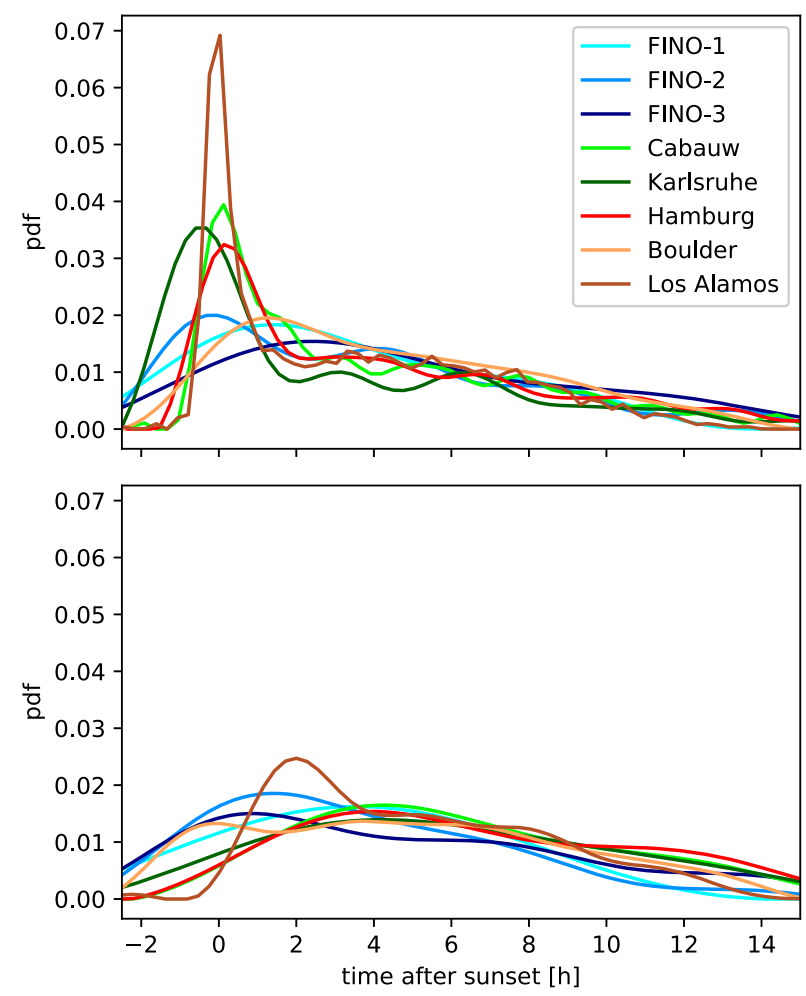

FIG. 4. Probability density distribution of the frequency of HMM regime transition times (for nights in which transitions occur) at the different tower sites for (top) wSBL-to-vSBL and (bottom) vSBL-to-wSBL transitions. All pdfs of the observations are calculated with the multivariate kernel density estimation by O'Brien et al. (2014, 2016).

In contrast to the seasonal variations of occurrence probabilities of very persistent nights, seasonal variations in the occurrence of transitions are relatively weak, particularly that of turbulence recovery events (Fig. 2). The occurrence of turbulence collapse events tends to decrease slightly at the American sites from summer (about 80\%) to winter (about $70 \%)$. In contrast, the frequency of such events increases slightly at Cabauw and the sites in the North Sea over the course of the year. One possible reason for small changes in the occurrence of turbulence collapse transitions is that the longest nights occur in winter, which is associated at these midlatitude stations with more synoptic-scale variability. Decreasing occurrence of wSBL-to-vSBL transitions in winter months may be related to stronger pressure gradient forces, which mechanically sustain turbulence and encourage very persistent wSBL nights (cf. section $3 c)$. However, the trend in the occurrence is very weak, consistent with the weak relationship between transition occurrences and external influences (as will be discussed in section $3 \mathrm{c}$ ). 

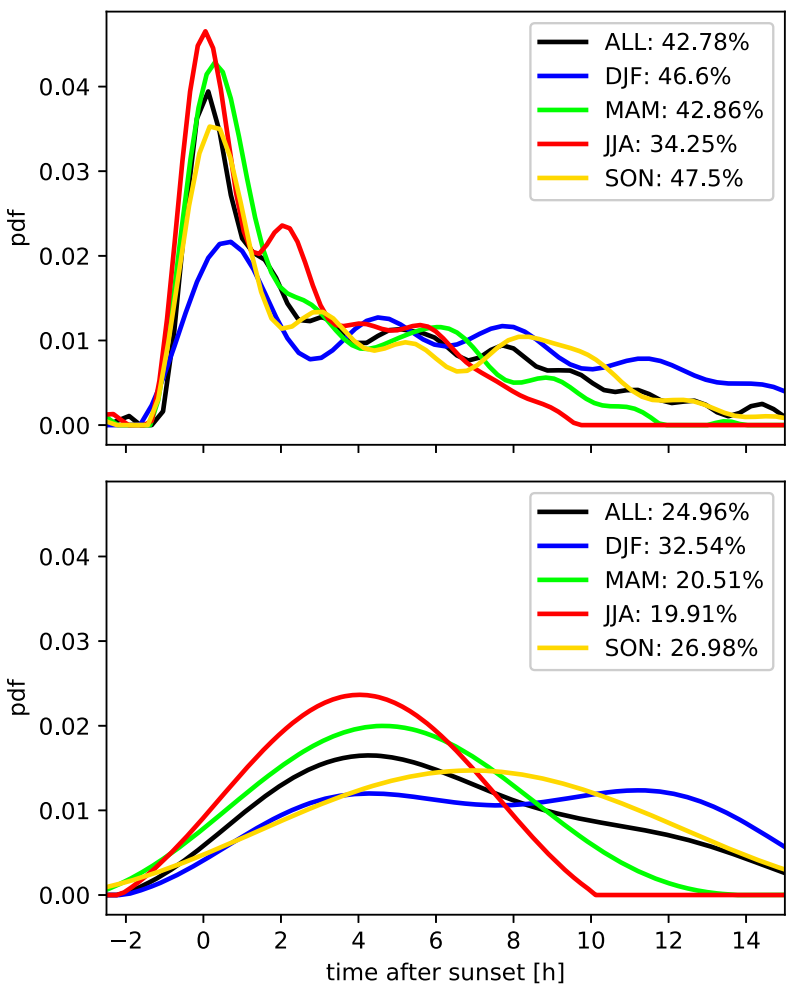

FIG. 5. Probability density distribution of the frequency of HMM regime seasonal (all seasons: black; winter: blue; spring: green; summer: red; fall: orange) transition times (for nights in which transitions occur) at Cabauw for (top) wSBL-to-vSBL and (bottom) vSBL-to-wSBL transitions. The percentages are the relative probabilities of the occurrence of, respectively, wSBL-to-vSBL and reverse transitions in a night. All pdfs are calculated with the multivariate kernel density estimation by O'Brien et al. $(2014,2016)$.

Not only single regime transitions in a night are a common SBL feature but also the occurrence of multiple transitions within a night. The occurrence probabilities of turbulence recovery events subsequent to turbulence collapses are much more similar across land-based stations than the general occurrence of at least one wSBL-to-vSBL transition (which is a necessary condition for subsequent recovery events to occur; Table 3), indicating that the occurrence of causes for vSBL-to-wSBL transitions might be only weakly location dependent. The probability of the occurrence of turbulence recovery events subsequent to a turbulence collapse increases with the durations of nights (Fig. 3, top panel). This increase of the probability of a turbulence recovery following turbulence collapse is consistent with the longer time available for such a transition to occur. Furthermore, longer nights occur in winter when pressure gradient forces are typically larger.

The occurrence of turbulence collapse events subsequent to turbulence recovery events are (with the
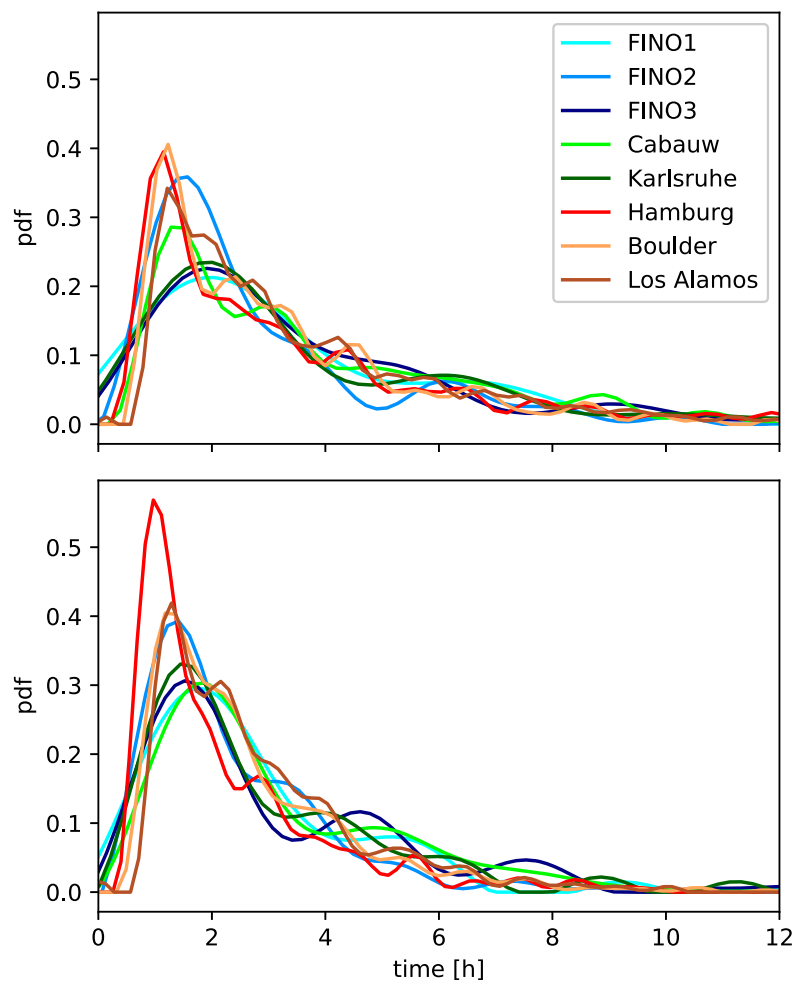

FIG. 6. Probability density function of the (top) vSBL event duration (time between a turbulence collapse and subsequent turbulence recovery event) and (bottom) wSBL event duration (time between a turbulence recovery event and a subsequent turbulence collapse) at the different tower sites as determined by the HMM analyses. All pdfs are calculated with the multivariate kernel density estimation by O'Brien et al. $(2014,2016)$.

exception of FINO-3) more probable at land-based stations than at sea-based stations (Table 3), likely due to the sustained radiative cooling at the land surface. Consistent with the statistics described above, the arid American sites exhibit the highest frequencies of such turbulence collapse events following preceding turbulence recovery events. Similar to the general occurrence of wSBL-to-vSBL transitions, the probabilities of such turbulence collapse events are relatively similar (or slightly declining) with increasing length of night (Fig. 3, bottom panel).

\section{b. Distributions of regime transition timing and event duration}

We now turn to the timing of regime transitions in those nights in which they occur. The wSBL-to-vSBL transition is caused by suppression of vertical turbulent fluxes, over land normally due to the radiative cooling at the surface (cf. AM19b). As a result, the collapse of turbulence at these stations occurs most often around sunset, when the surface radiative energy budget changes sign (Fig. 4, top panel). The sea-based 


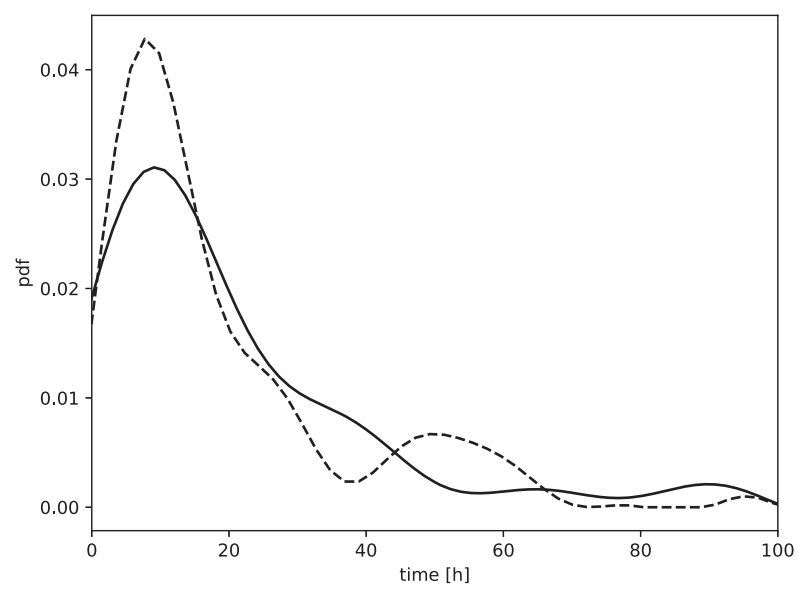

FIG. 7. Probability density function of the vSBL event duration (time between a turbulence collapse and subsequent turbulence recovery event; solid line) and wSBL event duration (time between a turbulence recovery event and a subsequent turbulence collapse; dashed line) at Dome $\mathrm{C}$ as determined by the HMM analysis. The pdfs are calculated with the multivariate kernel density estimation by O'Brien et al. (2014, 2016).

stations demonstrate smaller near-sunset probability maxima of wSBL-to-vSBL transitions as transitions at these sites are initiated by warm-air advection (cf. AM19b). Such advection events do not happen at fixed times of the day at most locations. A notable exception is FINO-2, which is surrounded by landmasses in most directions. Turbulence collapse due to the advection of warm air from land over water is more likely the warmer the advected air masses are. The highest temperatures over land are usually found in the afternoon and early evening. Due to its geographical location the advective time delay results in the largest occurrence frequency of turbulence collapse at FINO-2 being found near the evening transition (Dörenkämper et al. 2015). Beyond about $4 \mathrm{~h}$ after sunset, the probability of turbulence collapse is approximately the same at all stations.
The pdfs of the timing of turbulence recovery events are relatively flat, with weak maxima about $4-6 \mathrm{~h}$ after sunset (Fig. 4, bottom panel).

Across all tower sites, the frequencies of turbulence collapse and recovery events are in approximate statistical equilibrium from about $4 \mathrm{~h}$ after sunset to sunrise as both types of transitions are equally likely to occur at any time of the night (Fig. 4). This fact is consistent with the result that the occurrence probabilities of turbulence recovery events subsequent to a turbulence collapse are approximately the same across these stations: such events are unlikely to occur early in the night due to the recovery time required after collapse demonstrated below. Thus, the occurrence of the subsequent regime transitions becomes approximately independent of the specific location and time of the night and appears to occur randomly.

The steady decrease of transition frequencies with increasing durations of the night is related to seasonal variations of the length of the night. Otherwise, transition statistics depend only weakly on the season. For example, the frequencies of the timing of transitions in different seasons at Cabauw are similar to each other, each showing pronounced maxima in wSBL-to-vSBL transitions around sunset and statistical equilibrium between turbulence collapses and recoveries afterward (Fig. 5). Though the probabilities also decrease with increasing durations of the nights, the tails of the seasonal distributions are flatter than those of the wholeyear distributions. In particular, the winter season shows a less pronounced maximum in wSBL-to-vSBL transitions. Qualitatively similar results are obtained across all the other tower stations.

We now consider the distribution of SBL regime event duration. The mean vSBL event duration (the time between turbulence collapse and subsequent turbulence recovery events) is about $3-4 \mathrm{~h}$ across all sites at (Table 3, column 4). The mean wSBL event duration

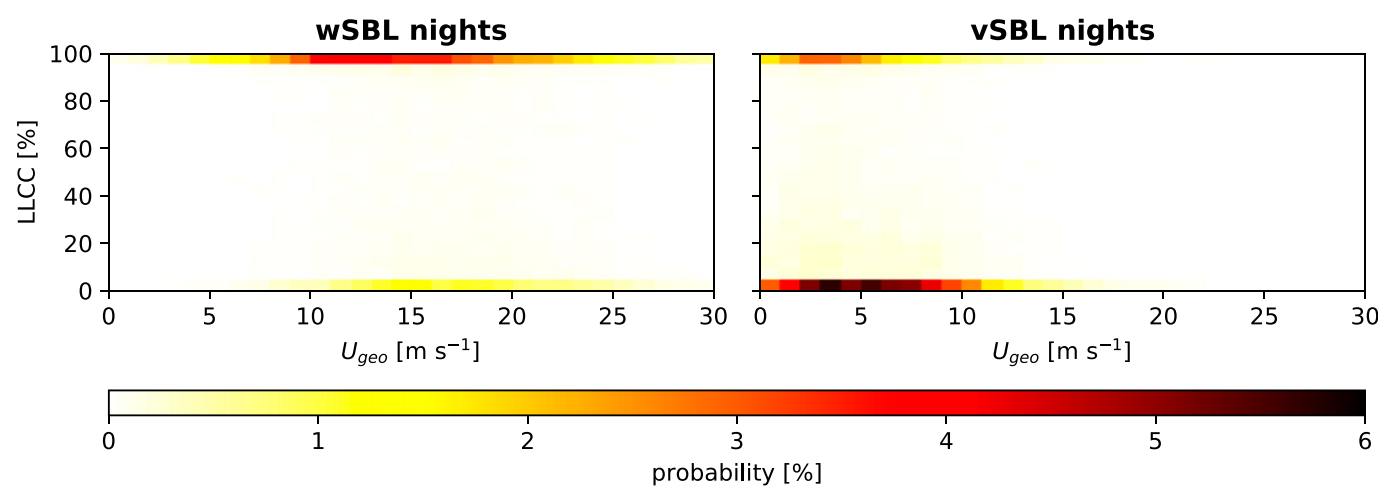

FIG. 8. Joint probability of the geostrophic wind $U_{\text {geo }}$ and the low-level cloud coverage (LLCC) for very persistent (left) wSBL and (right) vSBL nights at Cabauw. 


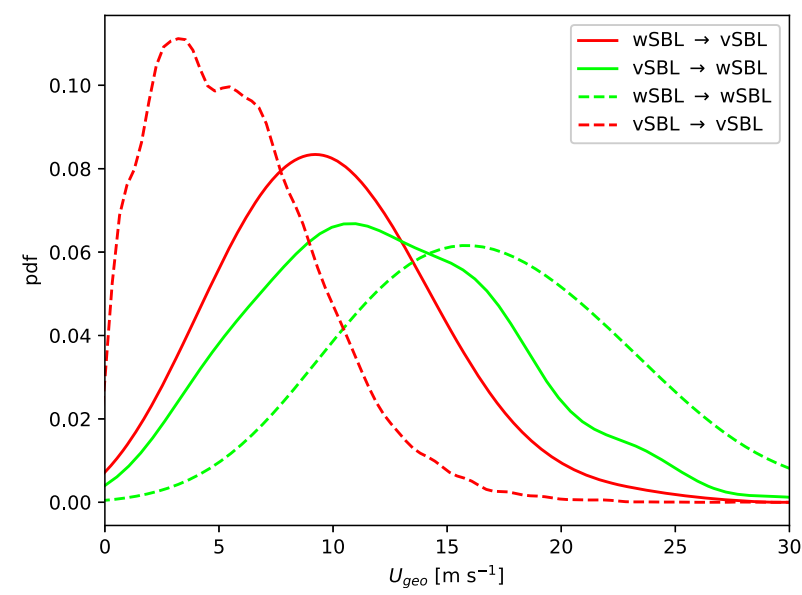

FIG. 9. Probability density functions of the geostrophic winds $U_{\text {geo }}$ for nights remaining exclusively in the wSBL (green dashed line) and the vSBL (red dashed line), and in the $3 \mathrm{~h}$ before and after transitions from the wSBL to the vSBL (red solid line), and in the $3 \mathrm{~h}$ before and after transitions from the vSBL to wSBL (green solid line) at Cabauw. All pdfs are calculated with the multivariate kernel density estimation by O'Brien et al. (2014, 2016).

(time between turbulence recovery event and the subsequent turbulence collapse) is $2.5-3 \mathrm{~h}$ (Table 3 , column 8 ), somewhat shorter than vSBL mean event durations.

The pdfs of the time between successive transitions show qualitatively similar structures across all tower sites (Fig. 6). In particular, these event duration pdfs show clear maxima about $1-2 \mathrm{~h}$ after the collapse, displaying a recovery period of about 1 or $2 \mathrm{~h}$ between transitions. Over land, factors contributing to the existence of such a recovery period are the time needed to build up enough shear, or for sufficiently strong intermittent turbulence events to occur, to break down the inversion after a turbulence collapse (vSBL-to-wSBL transition); or to cool down the nearsurface layers to rebuild a stably stratified temperature profile (wSBL-to-vSBL transition). Although all the distributions demonstrate a qualitatively similar shape, quantitative differences are evident, particularly within the recovery period of about $2 \mathrm{~h}$ after preceding transitions. Quantitative differences among the distributions are smaller for longer events. It is not clear why the SBL event durations demonstrate such qualitatively similar distributions, or why distributions of either type of event over land should resemble those over water.

It is a striking fact that at stations with a diurnal cycle the pdfs of event durations are largely insensitive to the surface type, the latitude, or the surrounding conditions. Furthermore, the similarity of vSBL and wSBL event duration pdfs is striking as different physical mechanisms lead to turbulence collapse and recovery

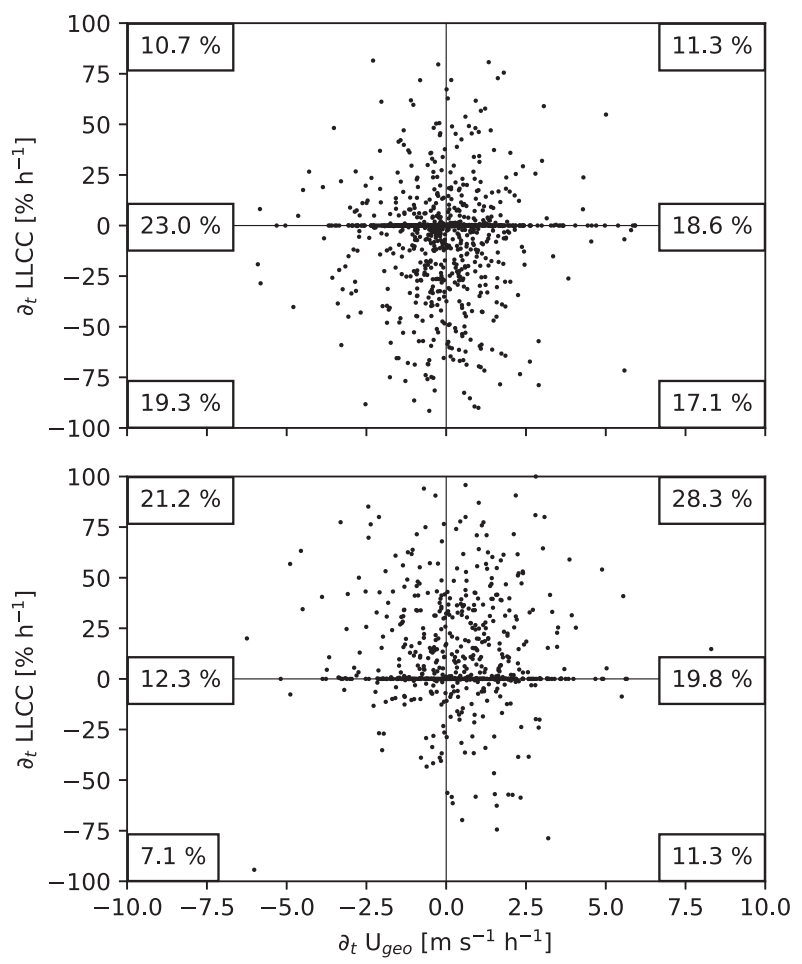

FIG. 10. Scatterplot of the tendency (as determined by linear regression) of the geostrophic wind $U_{\text {geo }}$ in the $90 \mathrm{~min}$ before and after SBL regime transitions and the low-level cloud-cover (LLCC) change of the 30-min means before and after SBL regime transitions for (top) wSBL-to-vSBL transitions and (bottom) reverse transitions at Cabauw. Relative occupation times of the quadrants are indicated as well as the relative occupation times of increasing and decreasing $U_{\text {geo }}$ conditioned on no LLCC changes.

transitions. An investigation of the physical controls on the quantitative details of the regime duration distributions, including the most likely durations of $1-2 \mathrm{~h}$, is outside of the scope of this study but an intriguing direction of future research.

At Dome C, wSBL and vSBL event durations also demonstrate the robust shape described above (Fig. 7). Again, the mean wSBL event duration is slightly shorter than the mean vSBL event duration. However, the recovery time is longer resulting in most likely event durations of about $10 \mathrm{~h}$ (about 4-5 times longer than at the other stations). The substantially longer durations at Dome $\mathrm{C}$ might be related to the fact that over the Antarctic glacier very strong and shallow vSBL conditions form (cf. van de Wiel et al. 2017; Vignon et al. 2017b; AM19b). A factor that could contribute to the longer event duration time scale at this site is that regime transitions are influenced by large-scale flow changes, which tend to occur on the time scale of days rather than hours (AM19b). 

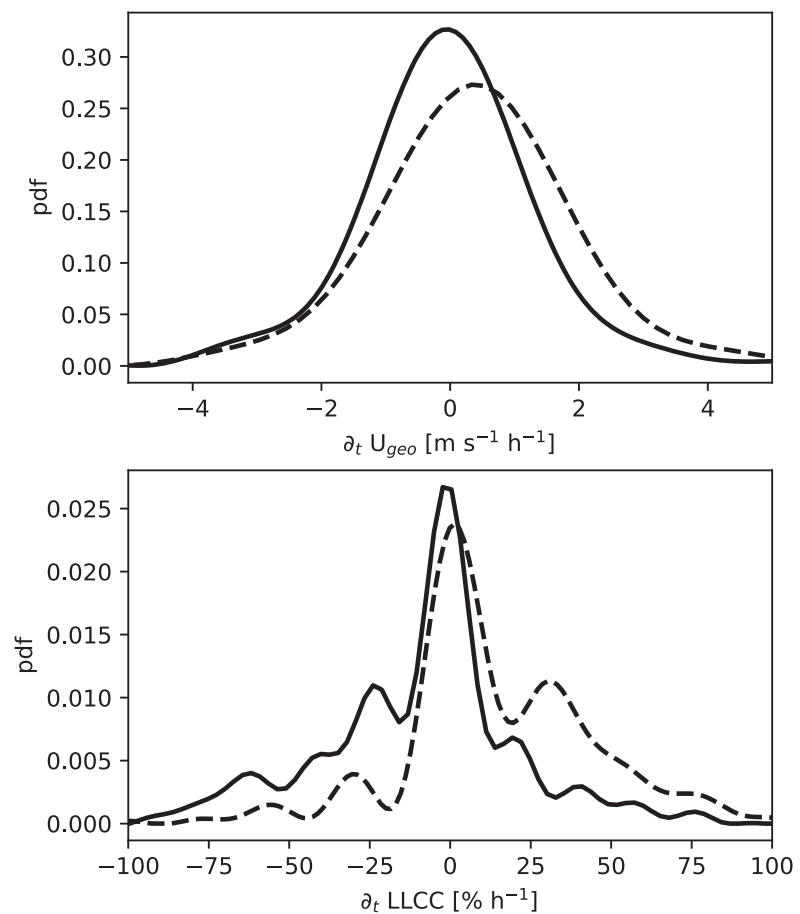

FIG. 11. (top) Pdfs of the tendency (as determined by linear regression) of the geostrophic wind $U_{\text {geo }}$ in the $90 \mathrm{~min}$ before and after wSBL-to-vSBL (solid) and reverse (dashed) transitions at Cabauw. (bottom) Conditional pdfs of the change of the 30-min means of low-level cloud cover (LLCC) before and after wSBL-to-vSBL (solid) and reverse (dashed) transitions at Cabauw. All pdfs are calculated with the multivariate kernel density estimation by O'Brien et al. (2014, 2016).

\section{c. The influence of external drivers on regime occupation}

As discussed in qualitative terms in the previous section, seasonal variations of the occurrence probabilities of very persistent nights and features of nights with SBL regime transitions appear to be related to seasonal changes of large-scale synoptic conditions. We now present a more detailed analysis of the relationship between regime occurrence probabilities at Cabauw and two external drivers: the external pressure gradient force and LLCC. The external pressure gradient force, as measured by $U_{\mathrm{geo}}$, is used to evaluate the mechanical driving of the SBL, while LLCC provides information regarding variations of the surface radiative energy budget. Overcast conditions increase the downwelling longwave radiation flux (LWD) reducing radiative cooling at the surface and weakening the strength of the inversion. Conversely, clear-sky conditions enhance the radiative cooling and favor strong inversions. As we have information about these external influences only at Cabauw, the following analysis concentrates on that site. Another potential external driver is the advection of warm air as discussed above (and in more detail in AM19b). A clear signal of warm air advection is only found in climatological features of SBL regime transitions at the sea-based and the glacial-based tower sites (cf. AM19b), although warmair advection aloft is likely to be important at times at Cabauw (Optis and Monahan 2017). Furthermore, the single-point tower observations do not provide the data necessary to qualitatively assess the role of horizontal temperature advection at Cabauw or other land-based stations.

We find that the very persistent wSBL is accompanied $63 \%$ of the time with overcast conditions (LLCC > $95 \%$ ) and about $16 \%$ of the time with clear-sky conditions (LLCC $<5 \%$ ). Conversely, $55 \%$ of the very persistent vSBL nights are accompanied by clear-sky conditions and only $22 \%$ by overcast conditions. In very persistent nights, tendencies of $U_{\text {geo }}$ are typically small; the resulting mechanical driving is therefore steady (not shown). The joint distribution of $U_{\text {geo }}$ and LLCC in the very persistent wSBL shows that in overcast conditions $U_{\text {geo }}$ is most likely to be between 10 and $20 \mathrm{~m} \mathrm{~s}^{-1}$ (Fig. 8, left panel). In contrast, for very persistent vSBL nights the most probable combination is low $U_{\text {geo }}$ (between 3 and $8 \mathrm{~m} \mathrm{~s}^{-1}$ ) with clear-sky conditions (Fig. 8, right panel). Overcast conditions are associated with the very persistent vSBL only for very low $U_{\text {geo }}$ values. These results quantify how in overcast (LLCC $>95 \%$ ) or clear-sky (LLCC $<5 \%$ ) conditions different $U_{\text {geo }}$ ranges distinguish the very persistent vSBL and the very persistent wSBL. For clear-sky conditions the value $U_{\text {geo }}$ of $12 \mathrm{~m} \mathrm{~s}^{-1}$ approximately separates the two regimes. This threshold value decreases to about $7 \mathrm{~m} \mathrm{~s}^{-1}$ under overcast conditions. These results are broadly consistent with findings of Monahan et al. (2015), in which regime occurrence was conditioned on values of external forcing (in contrast to the conditioning of external forcing on regime occupation considered here).

Values of the instantaneous $U_{\text {geo }}$ at times of regime transition exhibit relatively similar distributions for both turbulence collapse and recovery events: the probability distributions of $U_{\text {geo }}$ magnitudes at times of transitions range over very similar values (from 1 to about $25 \mathrm{~m} \mathrm{~s}^{-1}$ ) and the general shapes are substantially overlapping unimodal distributions with nearly equal maxima at about 9 and $10 \mathrm{~m} \mathrm{~s}^{-1}$, respectively, for turbulence collapse and recovery events (Fig. 9, solid lines). For $U_{\text {geo }}$ larger than about $15 \mathrm{~m} \mathrm{~s}^{-1}$, wSBL-tovSBL transitions are more likely than turbulence collapse and vice versa for weaker $U_{\text {geo }}$, demonstrating a modest systematic dependence of transition probabilities on $U_{\text {geo }}$. However, the substantially overlapping 

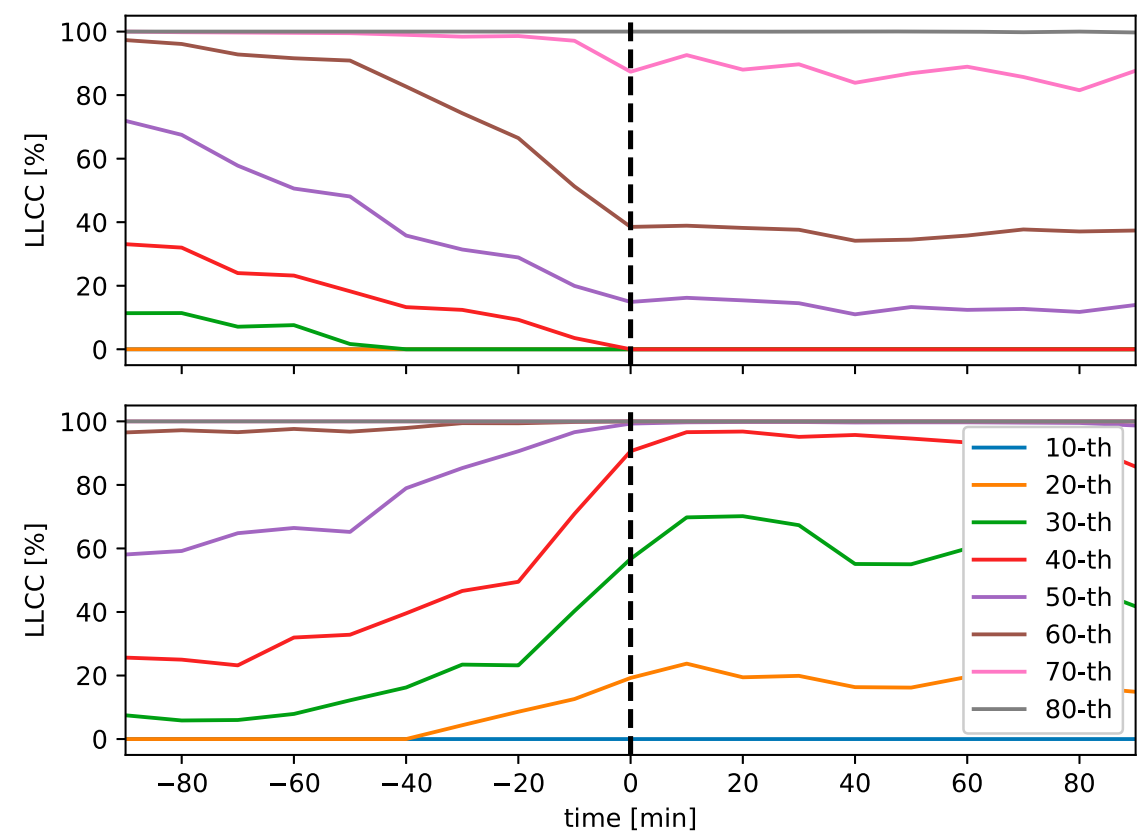

FIG. 12. Time evolution of low-level cloud-cover (LLCC) percentiles from $90 \mathrm{~min}$ before to 90 min after transitions at Cabauw of (top) wSBL-to-vSBL transitions and (bottom) vSBL-to-wSBL transitions.

distributions indicate that no clear deterministic relationship between the magnitude of $U_{\text {geo }}$ and the occurrence of specific transitions exists. Furthermore, the distributions of $U_{\text {geo }}$ at times of transition are centered in the region of overlap between the distributions of $U_{\text {geo }}$ during very persistent nights (Fig. 9, dashed lines). These results agree well with the finding of van der Linden et al. (2017) that there is no clear $U_{\text {geo }}$ threshold between the vSBL or wSBL.

In the absence of a clear threshold of $U_{\text {geo }}$ associated with regime transitions, we analyze the tendency of the geostrophic wind in the $90 \mathrm{~min}$ before and after the transitions in order to evaluate if changes in large-scale pressure gradient force can initiate a transition. The tendency is represented by the slope of a regression-based trend line. No strong relationship is evident between geostrophic wind tendency and regime transitions (Fig. 10). We find that turbulence collapse events are associated with both increasing and decreasing $U_{\text {geo }}$, with roughly equal probability (Fig. 10, top panel). Similar results are found for recovery events, of which roughly $60 \%$ are associated with an increase and $40 \%$ with a decrease in pressure gradient force (Fig. 10, bottom panel). Tendencies of $U_{\text {geo }}$ show approximately the same range of values during either kind of transition (Fig. 11, top panel). The maxima of the $U_{\text {geo }}$ tendency pdfs in the different transitions show the expected signs: decreasing $U_{\text {geo }}$ for the turbulence collapse and increasing for recovery. However, the values of these most likely values are very small relative to the breadths of the distributions and therefore this result does not imply any useful predictive skill.

Changes in LLCC have a stronger effect on transitions than those of $U_{\text {geo }}$. We first measure the change of the LLCC by subtracting 30-min averages following and preceding transitions (Fig. 10, vertical axis). The LLCC tendencies can then broadly be examined in three different classes: increasing, decreasing, and steady (no change). The wSBL-to-vSBL transition is associated about $35 \%$ of the time with decreasing LLCC and about $20 \%$ of the time with increasing LLCC (Fig. 10, top panel). No LLCC change is found for the rest of the transitions.

The pdf of LLCC tendency in times of wSBL-to-vSBL transitions has a peak around zero, as these transitions are most probable in the absence of cloud-cover tendencies (Fig. 11, bottom panel). Nevertheless, the negative skewness of this distribution shows that decreasing LLCC is more probable than increasing in times of turbulence collapse. A closer relationship is found between turbulence recovery events and cloud-cover tendency. An increasing LLCC is found in about $50 \%$ of recovery events, no LLCC change in about $30 \%$ of events, and only $20 \%$ of events are associated with a LLCC decrease (Fig. 10, bottom panel). While the most probable LLCC changes are around zero during 

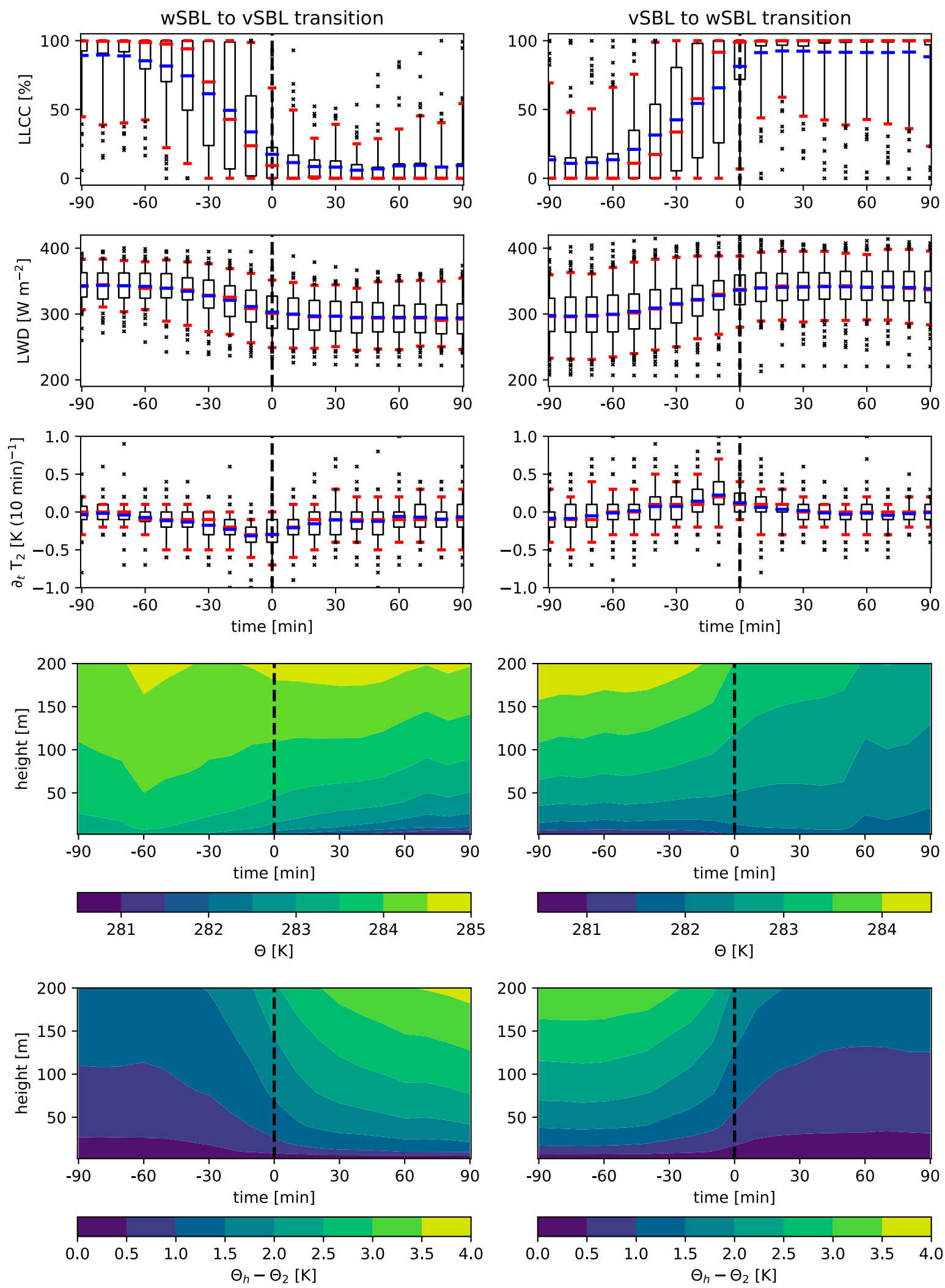

FIG. 13. Time evolution of the (left) wSBL-to-vSBL and (right) reverse transitions conditioned on the occurrence of low-level cloudcover change of more than $20 \% \mathrm{~h}^{-1}$ at Cabauw. Statistics $90 \mathrm{~min}$ before and after transitions at time $t=0$ (dashed reference line) are 
vSBL-to-wSBL transitions, the pdf is prominently positively skewed (Fig. 11).

We further analyze the relationship between LLCC changes and transitions by evaluating the evolution of LLCC quantiles across times of transitions. We find that LLCC changes associated with turbulence collapse or recovery events precede the transitions (Fig. 12). After the transitions the LLCC percentiles are relatively steady. More evidence of the causal relationship between LLCC changes and transitions comes from conditioning SBL regime transitions with LLCC changes of more than $20 \% \mathrm{~h}^{-1}$ (Fig. 13). This subset of transitions exhibit a clear structure with a substantial mean LLCC decrease (increase) preceding turbulence collapse (recovery) events (Fig. 13, first row). These LLCC changes are associated with an LWD decrease (increase) of about $50 \mathrm{Wm}^{-2}$ (Fig. 13, second row) and systematic temperature decreases (increases) at $2 \mathrm{~m}$ (Fig. 13, third row). The composite mean temperature and stratification (measured by the potential temperature difference between higher observational levels and the 2-m temperature) structures show cooling (warming) near the surface preceding transitions consistent with decreasing (increasing) LLCC changes (Fig. 13, rows 4 and 5). More detailed descriptions of the statevariable dynamics during times of transitions are discussed in AM19b. Analyses of lagged correlations between the LLCC and temperature changes show peaks at time lags of about 10-20 min confirming further that temperature fields respond to changes in LLCC (not shown). These results provide strong evidence for a causal influence of cloud-cover changes on transitions. Nonetheless, many transitions also occur without cloud-cover change, demonstrating that changes in clouds are not the only reason for SBL regime transitions. Higher clouds (above approximately $2000 \mathrm{~m}$ ) have no impact on transitions (not shown).

Even though no clear general dependence of tendencies in $U_{\text {geo }}$ on transitions can be found, the timing of the first transitions occurring in a night depends weakly on the nighttime mean geostrophic wind, denoted $\overline{U_{\text {geo }}}$ (Fig. 14). Larger values of $\overline{U_{\text {geo }}}$ are associated with later times of first turbulence collapses, indicating that larger shears sustain the turbulence longer before radiative cooling at the surface results in the transition. This dependence is weak, and the most probable time of turbulence collapse is observed to occur within the first $2 \mathrm{~h}$ after sunset for $\overline{U_{\text {geo }}}$ values between 1 and $30 \mathrm{~m} \mathrm{~s}^{-1}$. This weak dependence is found to be independent of the LLCC.

The timing of events of turbulence recovery is unaffected by the value of $\overline{U_{\text {geo }}}$ during nights. This result is consistent with the picture of the vSBL-to-wSBL transition resulting due to LLCC changes or due to intermittent turbulence events, which are unpredictable by the large-scale meteorological state (Rees and Mobbs 1988; Lang et al. 2018).

\section{Conclusions}

The regime sequences from hidden Markov model (HMM) analyses of the nighttime mean wind, wind speed shear, and stratification data at nine different land-, glacial-, and sea-based tower sites have been used in order to determine the occupation statistics of weakly and strongly stratified nocturnal boundary layer regimes (wSBL and vSBL, respectively). We have paid particular attention to differences between nights in which transitions occur and those without any regime transitions ("very persistent" nights). Both classes of nights are common at the stations considered; characterizing differences between the two is an important part of establishing the climatology of SBL regimes.

We find systematic changes in frequency of very persistent nights with variations in surface conditions: such nights are relatively rare in arid regions (Boulder and Los Alamos), more common in cloudier regions (Cabauw, Hamburg, and Karlsruhe), and most common at sea-based tower sites (FINO-1, FINO-2, and FINO-3). At most but not all land-based stations, very persistent wSBL nights are approximately as likely as very persistent vSBL nights. Across all sites the occurrence of very persistent nights depends strongly on the season. Very persistent wSBL are more frequent in wintertime than in summer whereas very persistent vSBL nights are more frequent in summer nights (with the exception of Boulder).

In contrast to very persistent nights, we find that at all stations the occurrence of SBL regime transitions is only weakly dependent on the season. The occurrence frequency of wSBL-to-vSBL transitions (turbulence collapse) is closely tied to the diurnal cycle.

\footnotetext{
$\longleftarrow$

shown. (top three rows) Distributions of low-level cloud cover (LLCC), downwelling longwave radiation at the surface (LWD), and 2-m temperature change within a 10-min observational interval $\left(\partial_{t} T_{2}\right)$ illustrated by interquartile range (box), 5 th-95th-percentile range (outer red bars), median value (red lines), and mean value (blue lines). (bottom two rows) Composite means of potential temperature $\Theta$ and stratification (measured by the potential temperature difference between each observational level and the 2-m temperature; $\Theta_{h}-\Theta_{2}$ ).
} 


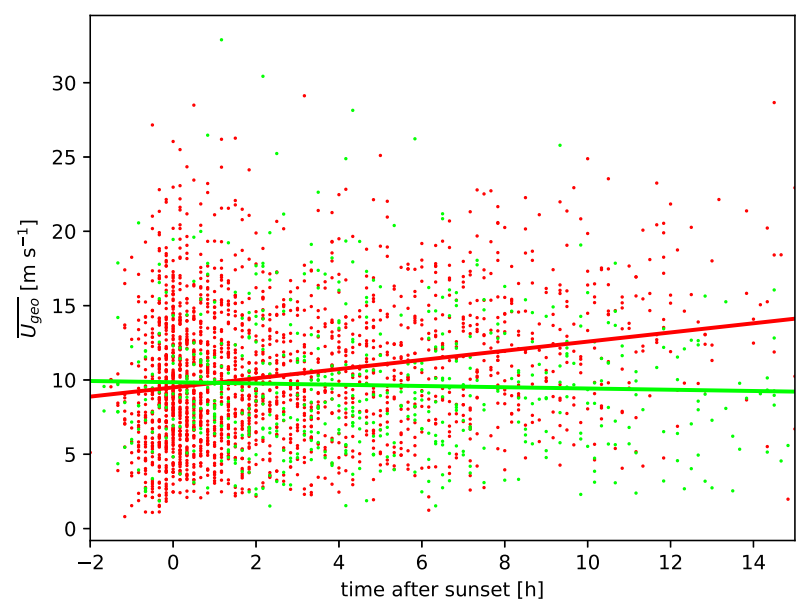

FIG. 14. Scatterplot of the timing of first turbulence collapse (red) and first event of turbulence recovery (green) in a night depending on the mean geostrophic wind $\overline{U_{\text {geo }}}$ of each night. Regression lines of $\overline{U_{\text {geo }}}$ on collapse and recovery times are also illustrated.

Across land-based stations, surface radiative cooling starts around sunset and leads to a maximum in the transition frequency from wSBL to vSBL conditions near this time. Across sea-based stations only very weak maxima in the timing of transitions are present as transitions are caused by advection of warm air aloft (AM19b), which is not generally closely tied to the diurnal cycle. The frequency of occurrence of turbulence recovery (vSBL-to-wSBL transitions), on the other hand, shows a weaker dependence on the time after sunset. After about four hours after sunset frequencies of the two regime transitions are in approximate statistical equilibrium indicating that transitions during this period depend on internal or external influences that are not tied to the diurnal cycle.

The probability density functions (pdfs) of the regime event duration (the timing between one transition and the next) show the same structure for wSBL and vSBL episodes across land- and sea-based stations. Both distributions are characterized by an initial recovery time of approximately $1-2 \mathrm{~h}$ before a subsequent transition becomes probable. The fact that these event duration pdfs are qualitatively consistent across these stations shows their insensitivity to specific surface types, meteorological setting, or the surrounding conditions. The physical reasons for this generic structure, which are not consistent with the Markov assumption underlying the HMM analysis, are unclear and represent an important direction of future research. Similar to the other stations, at Dome $\mathrm{C}$ (where diurnal effects do not modulate the regime dynamics) the event duration pdfs show the same shape and character.
However, the recovery time is about $4-5$ times longer than at the other stations, which could be related to a stronger link between transition occurrences and synoptic changes.

The non-Markov behavior evident in the distributions of regime event durations and the timing of the wSBLto-vSBL transition does not invalidate the use of an HMM analysis for classification purposes of data into wSBL and vSBL regimes. Estimated regime sequences (allowing the affiliation of each data point with the wSBL or vSBL) are only weakly sensitive to transition probabilities describing the hidden Markov chain (Abraham et al. 2019).

Analysis of the dependence of the occurrence of very persistent nights on external drivers at Cabauw reveals a clear separation of the prevailing pressure gradient force (as measured by the geostrophic wind $U_{\text {geo }}$ ) between very persistent nights in each regime. Another external driver on the SBL dynamics is the low-level cloud coverage (LLCC). Very persistent wSBL nights are most likely to occur under overcast conditions with strong $U_{\text {geo }}$ while very persistent vSBL nights are most likely under clear-sky conditions with weak $U_{\text {geo }}$. An approximate threshold of $U_{\text {geo }}=12 \mathrm{~m} \mathrm{~s}^{-1}$ separates very persistent wSBL and vSBL nights under clear-sky conditions. This threshold decreases with increasing LLCC.

Although a reasonably clear (if cloud-cover dependent) threshold of $U_{\text {geo }}$ separates very persistent wSBL and vSBL nights, the distributions of the magnitude of $U_{\text {geo }}$ at times of SBL regime transitions are broad and overlapping. The $U_{\text {geo }}$ does not appear to provide information regarding the occurrence of regime transitions within a night. Only the timing of the first turbulence collapse depends weakly on the nighttime average $\overline{U_{\text {geo }}}$ values, such that larger $\overline{U_{\text {geo }}}$ lead to somewhat later turbulence collapse. In the same way, SBL regime transitions cannot be associated with a particular magnitude of LLCC. Probability distributions of tendencies of $U_{\text {geo }}$ within $180 \mathrm{~min}$ of transitions show very similar broad distributions centered at zero suggesting that neither wSBL-to-vSBL transitions nor vSBL-to-wSBL transitions generally result from changes in large-scale mechanical driving. In contrast, changes in LLCC have a larger effect on transitions in the SBL. During wSBL-to-vSBL transitions LLCC is more likely to decrease or to stay the same than to increase. Half of vSBL-to-wSBL transitions are accompanied by LLCC increase. These LLCC changes are found to precede the regime transitions and can be interpreted as initiating SBL transitions due to lagged changes in temperature structure. However, many regime transitions are observed to occur without changes in LLCC. 
Our results indicate that SBL regime transitions do not demonstrate a clear deterministic relationship with the external state-variable LLCC or geostrophic forcing. This result could indicate that regime dynamics are determined by the internal dynamics of the boundary layer. These internal boundary layer mechanisms are discussed in more detail in AM19b in which we concentrate on the composite behavior of the boundary layer structure across transitions and during very persistent nights. One internal mechanism to the SBL that has the potential to drive transitions is the formation of low-level jets, which is favored by the vSBL regime. The low-level jet has been associated with substantial turbulence production due to strong shears, which can excite intermittent turbulence events (e.g., Banta et al. 2003, 2006, 2007; Ohya et al. 2008; Baas et al. 2009; Cava et al. 2019). If transitions are related to the low-level jet its strength and position might encompass a relationship with the occurrence or absence of vSBL-to-wSBL transitions. The effect of low-level jets on the vSBL regime dynamics will be the subject of a future study.

As discussed in section 1, another approach proposed to simulate SBL regime dynamics in weather and climate models is to account for them by explicitly stochastic parameterizations. This study strengthens the argument for the need of such parameterizations due to the absence of, first, a clear deterministic relationship between SBL regime transitions and external drivers. The absence of a simple deterministic relationship between internal variables (such as temperatures or wind speeds) and regime occupation is demonstrated by the fact that pdfs of state variables conditioned on the SBL regimes overlap considerably (AM19a). This study quantifies the obtained regime occupation and transition statistics such a parameterization should capture. We discuss a prototype of such a stochastic parameterization in Abraham et al. (2019). The existence of a nonzero recovery time between transitions (indicating that dynamics beyond a simple two-state Markov chain are required to physically model transitions between regimes) and nonstationarities such as near-sunset maximum in wSBL-to-vSBL transition probability imply that simple formulations of such stochastic effects may not be adequate.

In this study we have focused on the climatological regime occupation statistics of the weakly and very stably stratified regimes of the SBL. In AM19b, the last paper in this series, we will focus on the structure of meteorological state variables during regime transitions and compare these to their structure in very persistent nights. This paper also investigates in more detail differences between tower sites' regime structures and temporal evolution.

Acknowledgments. We thank a number of individuals and institutes for their willingness to share their tower data, which were indispensable in carrying out this extensive comparison of SBL structures at different location sites. Our acknowledgements are presented in the order that the tower stations were presented in the paper, but we are equally thankful to all. The NOAA Earth System Research Laboratory's (ESRL) Physical Sciences Division (PSD) operates the Boulder Atmospheric Observatory (BAO) tower and makes the data publicly available (information how to obtain the data is given on https://www.esrl.noaa.gov/ psd/technology/bao/site/). The Royal Netherlands Meteorological Institute (KNMI) is thanked for providing tower data from the Cabauw Experimental Site for Atmospheric Research (CESAR) (which can be downloaded at http://www.cesar-database.nl). Fred Bosveld from the KNMI is acknowledged in particular for providing one year of turbulence data from CESAR. Felix Ament and Ingo Lange provided an extensive amount of Reynolds-averaged and turbulence data from the Wettermast Hamburg of the Meteorological Institute of the University of Hamburg. Martin Kohler and the Institute for Meteorology and Climate Research of the Karlsruhe Institute of Technology (KIT) provided observations from the turbulence and meteorological mast in Karlsruhe. The French and Italian polar institutes (IPEV and PANRA, respectively) that operate the Dome C observatory in Antarctica are acknowledged for providing data through IPEV (program CALVA 1013), INSU/LEFE (GABLS4 and DEPHY2), and OSUG (GLACIOCLIM). The data are available on the CALVA website (http:// lgge.osug.fr/ genthon/calva/home.shtml). The team of the Los Alamos National Laboratory (LANL) are thanked making data from the Environmental Monitoring Plan (EMP) freely available (which can be downloaded from http://environweb.lanl.gov/ weathermachine/data_request_green_weather.asp). The Bundesamt für Seeschifffahrt und Hydrographie (BSH), the Bundesministeriums für Wirtschaft und Energie (BMWi), the Projektträger Jülich (PTJ), and Olaf Outzen are thanked for granting access to the data from the offshore research platforms FINO-1, FINO-2, and FINO-3 in Germany.

Carsten Abraham and Adam H. Monahan are supported by the Natural Sciences and Engineering Research Council Canada (NSERC). The authors thank Yanping He, Amber Holdsworth, Ivo G. S. van Hooijdonk, Norman McFarlane, Ron McTaggart-Cowan, and Bas J. H. van de 
Wiel for useful discussions as well as three anonymous reviewers whose suggestions substantially improved this manuscript.

\section{REFERENCES}

Abraham, C., and A. H. Monahan, 2019a: Climatological features of the weakly and very stably stratified nocturnal boundary layers. Part I: State variables containing information about regime occupation. J. Atmos. Sci., 76, 3455-3484, https:// doi.org/10.1175/JAS-D-18-0261.1.

_ and - 2019b: Climatological features of the weakly and very stably stratified nocturnal boundary layers. Part III: The structure of meteorological state variables in persistent regime nights and across regime transitions. J. Atmos. Sci., 76, 3505-3527, https://doi.org/10.1175/JAS-D-18-0274.1.

- A. M. Holdsworth, and A. H. Monahan, 2019: A prototype stochastic parameterization of regime behaviour in the stably stratified atmospheric boundary layer. Nonlinear Processes Geophys., in press.

Acevedo, O. C., and D. R. Fitzjarrald, 2003: In the core of the night-effects of intermittent mixing on a horizontally heterogeneous surface. Bound.-Layer Meteor., 106, 1-33, https:// doi.org/10.1023/A:1020824109575.

— L. Mahrt, F. S. Puhales, F. D. Costa, L. E. Medeiros, and G. A. Degrazia, 2016: Contrasting structures between the decoupled and coupled states of the stable boundary layer. Quart. J. Roy. Meteor. Soc., 142, 693-702, https://doi.org/10.1002/qj.2693.

Ansorge, C., and J. P. Mellado, 2014: Global intermittency and collapsing turbulence in the stratified planetary boundary layer. Bound.-Layer Meteor., 153, 89-116, https://doi.org/ 10.1007/s10546-014-9941-3.

Baas, P., F. C. Bosveld, H. K. Baltink, and A. A. M. Holtslag, 2009: A climatology of nocturnal low-level jets at Cabauw. J. Appl. Meteor. Climatol., 48, 1627-1642, https://doi.org/10.1175/ 2009JAMC1965.1.

Banta, R. M., Y. L. Pichugina, and R. K. Newsom, 2003: Relationship between low-level jet properties and turbulence kinetic energy in the nocturnal stable boundary layer. J. Atmos. Sci., 60, 2549-2555, https://doi.org/ 10.1175/1520-0469(2003)060<2549:RBLJPA $>2.0$. CO 2 .

, — - and W. A. Brewer, 2006: Turbulent velocity-variance profiles in the stable boundary layer generated by a nocturnal low-level jet. J. Atmos. Sci., 63, 2700-2719, https://doi.org/ 10.1175/JAS3776.1.

— L. Mahrt, D. Vickers, J. Sun, B. B. Balsley, Y. L. Pichugina, and E. J. Williams, 2007: The very stable boundary layer on nights with weak low-level jets. J. Atmos. Sci., 64, 3068-3090, https://doi.org/10.1175/JAS4002.1.

Barthlott, C., N. Kalthoff, and F. Fiedler, 2003: Influence of highfrequency radiation on turbulence measurements on a $200 \mathrm{~m}$ tower. Meteor. Z, 12, 67-71, https://doi.org/10.1127/0941-2948/ 2003/0012-0067.

Bechtold, P., M. Köhler, T. Jung, F. Doblas-Reyes, M. Leutbecher, M. J. Rodwell, F. Vitart, and G. Balsamo, 2008: Advances in simulating atmospheric variability with the ECMWF model: From synoptic to decadal time-scales. Quart. J. Roy. Meteor. Soc., 134, 1337-1351, https://doi.org/10.1002/qj.289.

Beeken, A., T. Neumann, and A. Westerhellweg, 2008: Five years of operation of the first offshore wind research platform in the German Bight-FINO1. German Wind Energy Institute Tech. Rep., 5 pp., http://www.dewi.de/dewi/fileadmin/pdf/ publications/Publikations/5_Beeken.pdf.
Blumen, W., 1984: An observational study of instability and turbulence in nighttime drainage winds. Bound.-Layer Meteor., 28, 245-269, https://doi.org/10.1007/BF00121307.

_ R. Banta, S. P. Burns, D. C. Fritts, R. Newsom, G. S. Poulos, and J. Sun, 2001: Turbulence statistics of a Kelvin-Helmholtz billow event observed in the night-time boundary layer during the Cooperative Atmosphere-Surface Exchange Study field program. Dyn. Atmos. Oceans, 34, 189-204, https://doi.org/ 10.1016/S0377-0265(01)00067-7.

Bosveld, F. C., and Coauthors, 2014: The third GABLS intercomparison case for evaluation studies of boundarylayer models. Part B: Results and process understanding. Bound.-Layer Meteor., 152, 157-187, https://doi.org/10.1007/ s10546-014-9919-1.

Bowen, B. M., J. A. Baars, and G. L. Stone, 2000: Nocturnal wind direction shear and its potential impact on pollutant transport. J. Appl. Meteor. Climatol., 39, 437-445, https://doi.org/ 10.1175/1520-0450(2000)039<0437:NWDSAI $>2.0 . C O ; 2$.

Brümmer, B., I. Lange, and H. Konow, 2012: Atmospheric boundary layer measurements at the $280 \mathrm{~m}$ high Hamburg weather mast 1995-2011: Mean annual and diurnal cycles. Meteor. Z., 21, 319-335, https://doi.org/10.1127/0941-2948/ 2012/0338.

Cava, D., L. Mortarini, U. Giostra, O. Acevedo, and G. Katul, 2019: Submeso motions and intermittent turbulence across a nocturnal low-level jet: A self-organized criticality analogy. Bound.-Layer Meteor., 172, 17-43, https://doi.org/10.1007/ s10546-019-00441-8.

de Bruin, H. A. R., 1994: Analytic solutions of the equations governing the temperature fluctuation method. Bound.-Layer Meteor., 68, 427-432, https://doi.org/10.1007/BF00706800.

Derbyshire, S. H., 1999: Boundary-layer decoupling over cold surfaces as a physical boundary-instability. Bound.-Layer Meteor., 90, 297-325, https://doi.org/10.1023/A:1001710014316.

Dethloff, K., C. Abegg, A. Rinke, I. Hebestadt, and V. F. Romanov, 2001: Sensitivity of Arctic climate simulations to different boundary-layer parameterizations in a regional climate model. Tellus, 53A, 1-26, https://doi.org/10.3402/ tellusa.v53i1.12176.

Dörenkämper, M., B. Witha, G. Steinfeld, D. Heinemann, and M. Kühn, 2015: The impact of stable atmospheric boundary layers on wind-turbine wakes within offshore wind farms. J. Wind Eng. Ind. Aerodyn., 144, 146-153, https://doi.org/ 10.1016/j.jweia.2014.12.011.

Edwards, J. M., 2009: Radiative processes in the stable boundary layer: Part II. The development of the nocturnal boundary layer. Bound.-Layer Meteor., 131, 127-146, https://doi.org/ 10.1007/S10546-009-9363-9.

— J. R. McGregor, M. R. Bush, and F. J. A. Bornemann, 2011: Assessment of numerical weather forecasts against observations from Cardington: Seasonal diurnal cycles of screen-level and surface temperatures and surface fluxes. Quart. J. Roy. Meteor. Soc., 137, 656-672, https://doi.org/10.1002/qj.742.

Fischer, J.-G., C. Senet, O. Outzen, A. Schneehorst, and K. Herklotz, 2012: Regional oceanographic distinctions in the south-eastern part of the North Sea: Results of two years of monitoring at the research platforms FINO1 and FINO3. 11th German Wind Energy Conf., Bremen, Germany, DEWI.

Floors, R., A. Peña, and S.-E. Gryning, 2015: The effect of baroclinicity on the wind in the planetary boundary layer. Quart. J. Roy. Meteor. Soc., 141, 619-630, https://doi.org/ 10.1002/qj.2386. 
Genthon, C., M. S. Town, D. Six, V. Favier, S. Argentini, and A. Pellegrini, 2010: Meteorological atmospheric boundary layer measurements and ECMWF analyses during summer at Dome C, Antarctica. J. Geophys. Res., 115, D05104, https:// doi.org/10.1029/2009JD012741.

—_, D. Six, H. Gallée, P. Grigioni, and A. Pellegrini, 2013: Two years of atmospheric boundary layer observations on a $45-\mathrm{m}$ tower at Dome $\mathrm{C}$ on the Antarctic plateau. J. Geophys. Res. Atmos., 118, 3218-3232, https://doi.org/10.1002/ JGRD.50128.

Gerbig, C., S. Körner, and J. C. Lin, 2008: Vertical mixing in atmospheric tracer transport models: Error characterization and propagation. Atmos. Chem. Phys., 8, 591-602, https://doi.org/ 10.5194/acp-8-591-2008.

Grachev, A. A., C. W. Fairall, P. O. G. Persson, E. L. Andreas, and P. S. Guest, 2005: Stable boundary-layer scaling regimes: The SHEBA data. Bound.-Layer Meteor., 116, 201-235, https:// doi.org/10.1007/s10546-004-2729-0.

_- , E. L. Andreas, C. W. Fairall, P. S. Guest, and P. O. G. Persson, 2008: Turbulent measurements in the stable atmospheric boundary layer during SHEBA: Ten years after. Acta Geophys., 56, 142-166, https://doi.org/10.2478/ S11600-007-0048-9.

$-, \ldots,-, \ldots$, and $—, 2013$ : The critical Richardson number and limits of applicability of local similarity theory in the stable boundary layer. Bound.-Layer Meteor., 147, 51-82, https://doi.org/10.1007/s10546-012-9771-0.

Gryning, S.-E., R. Floors, A. Peña, E. Batchvarova, and B. Brümmer, 2016: Weibull wind-speed distribution parameters derived from a combination of wind-lidar and tall-mast measurements over land, coastal and marine sites. Bound.-Layer Meteor., 159, 329-348, https://doi.org/ 10.1007/s10546-015-0113-x.

He, Y., N. A. McFarlane, and A. H. Monahan, 2012: The influence of boundary layer processes on the diurnal variation of the climatological near-surface wind speed probability distribution over land. J. Climate, 25, 6441-6458, https://doi.org/ 10.1175/JCLI-D-11-00321.1.

Holtslag, A. A. M., and Coauthors, 2013: Stable atmospheric boundary layers and diurnal cycles: Challenges for weather and climate models. Bull. Amer. Meteor. Soc., 94, 1691-1706, https://doi.org/10.1175/BAMS-D-11-00187.1.

Kaimal, J. C., and J. E. Gaynor, 1983: The Boulder Atmospheric Observatory. J. Appl. Meteor. Climatol., 22, 863-880, https:// doi.org/10.1175/1520-0450(1983)022<0863:TBAO >2.0.CO;2.

Kalthoff, N., and B. Vogel, 1992: Counter-current and channelling effect under stable stratification in the area of Karlsruhe. Theor. Appl. Climatol., 45, 113-126, https://doi.org/10.1007/ BF00866400.

Kohler, M., J. Metzger, and N. Kalthoff, 2018: Trends in temperature and wind speed from 40 years of observations at a 200-m high meteorological tower in southwest Germany. Int. J. Climatol., 38, 23-34, https://doi.org/10.1002/joc.5157.

Kyselý, J., and E. Plavcová, 2012: Biases in the diurnal temperature range in central Europe in an ensemble of regional climate models and their possible causes. Climate Dyn., 39, 1275-1286, https://doi.org/10.1007/s00382-011-1200-4.

Lang, F., D. Belušić, and S. Siems, 2018: Observations of winddirection variability in the nocturnal boundary layer. Bound.-Layer Meteor., 166, 51-68, https://doi.org/10.1007/ s10546-017-0296-4.

Mahrt, L., 1998a: Nocturnal boundary-layer regimes. Bound.-Layer Meteor., 88, 255-278, https://doi.org/10.1023/A:1001171313493.
_ 1998b: Stratified atmospheric boundary layers and breakdown of models. Theor. Comput. Fluid Phys., 11, 263-279, https://doi.org/10.1007/s001620050093.

—_, 2010: Common microfronts and other solitary events in the nocturnal boundary layer. Quart. J. Roy. Meteor. Soc., 136, 1712-1722, https://doi.org/10.1002/qj.694.

_ 2011: The near-calm stable boundary layer. Bound.-Layer Meteor., 140, 343-360, https://doi.org/10.1007/s10546-011-9616-2. _ 2014: Stably stratified atmospheric boundary layers. Annu. Rev. Fluid Mech., 46, 23-45, https://doi.org/10.1146/annurevfluid-010313-141354.

Malhi, Y. S., 1995: The significance of the dual solutions for heat fluxes measured by the temperature fluctuation method in stable conditions. Bound.-Layer Meteor., 74, 389-396, https:// doi.org/10.1007/BF00712379.

Mauritsen, T., and G. Svensson, 2007: Observations of stably stratified shear-driven atmospheric turbulence at low and high Richardson numbers. J. Atmos. Sci., 64, 645-655, https:// doi.org/10.1175/JAS3856.1.

Medeiros, B., C. Deser, R. A. Tomas, and J. E. Kay, 2011: Arctic inversion strength in climate models. J. Climate, 24, 47334740, https://doi.org/10.1175/2011JCLI3968.1.

Monahan, A. H., T. Rees, Y. He, and N. McFarlane, 2015: Multiple regimes of wind, stratification, and turbulence in the stable boundary layer. J. Atmos. Sci., 72, 3178-3198, https://doi.org/ 10.1175/JAS-D-14-0311.1.

Nappo, C., J. Sun, L. Mahrt, and D. Belušić, 2014: Determining wave-turbulence interactions in the stable boundary layer. Bull. Amer. Meteor. Soc., 95, ES11-ES13, https://doi.org/ 10.1175/BAMS-D-12-00235.1.

Newsom, R. K., and R. M. Banta, 2003: Shear-flow instability in the stable nocturnal boundary layer as observed by Doppler lidar during CASES-99. J. Atmos. Sci., 60, 16-33, https://doi.org/ 10.1175/1520-0469(2003)060<0016:SFIITS $>2.0 . C O ; 2$.

Nieuwstadt, F. T. M., 1984: The turbulent structure of the stable, nocturnal boundary layer. J. Atmos. Sci., 41, 2202-2216, https:// doi.org/10.1175/1520-0469(1984)041<2202:TTSOTS>2.0.CO;2.

O'Brien, T. A., W. D. Collins, S. A. Rauscher, and T. D. Ringler, 2014: Reducing the computational cost of the ECF using a nuFFT: A fast and objective probability density estimation method. Comput. Stat. Data Anal., 79, 222-234, https://doi.org/ 10.1016/j.csda.2014.06.002.

_- K. Kashinath, N. R. Cavanaugh, W. D. Collins, and J. P. O'Brien, 2016: A fast and objective multidimensional kernel density estimation method: fastKDE. Comput. Stat. Data Anal., 101, 148-160, https://doi.org/10.1016/ j.csda.2016.02.014.

Ohya, Y., R. Nakamura, and T. Uchida, 2008: Intermittent bursting of turbulence in a stable boundary layer with low-level jet. Bound.-Layer Meteor., 126, 349-363, https://doi.org/10.1007/ s10546-007-9245-y.

Optis, M., and A. Monahan, 2017: A comparison of equilibrium and time-evolving approaches to modeling the wind profile under stable stratification. J. Appl. Meteor. Climatol., 56, 1365-1382, https://doi.org/10.1175/JAMC-D-16-0324.1.

, - _ and F. C. Bosveld, 2016: Limitations and breakdown of Monin-Obukhov similarity theory for wind profile extrapolation under stable stratification. Wind Energy, 19, 1053-1072, https://doi.org/10.1002/we.1883.

Pahlow, M., M. B. Parlange, and F. Porté-Agel, 2001: On MoninObukhov similarity in the stable atmospheric boundary layer. Bound.-Layer Meteor., 99, 225-248, https://doi.org/ 10.1023/A:1018909000098. 
Poulos, G. S., and Coauthors, 2002: CASES-99: A comprehensive investigation of the stable nocturnal boundary layer. Bull. Amer. Meteor. Soc., 83, 555-582, https://doi.org/10.1175/15200477(2002)083<0555:CACIOT > 2.3.CO;2.

Rabiner, L. R., 1989: A tutorial on hidden Markov models and selected applications in speech recognition. Proc. IEEE, 77, 257-286, https://doi.org/10.1109/5.18626.

Rees, J. M., and S. D. Mobbs, 1988: Studies of internal gravity waves at Halley Base, Antarctica, using wind observations. Quart. J. Roy. Meteor. Soc., 114, 939-966, https://doi.org/ 10.1002/QJ.49711448206.

Rishel, J., S. Johnson, and D. Holt, 2003: Meteorological monitoring at Los Alamos. Los Alamos National Laboratory Rep. LA-UR-039097, 36 pp., https://envweb.lanl.gov/weathermachine/downloads/ LA-UR-03-8097_webcopy.pdf.

Sorbjan, Z., 1986: On similarity in the atmospheric boundary layer. Bound.-Layer Meteor., 34, 377-397, https://doi.org/10.1007/ BF00120989.

Sterk, H. A. M., G. J. Steeneveld, and A. A. M. Holtslag, 2013: The role of snow-surface coupling, radiation, and turbulent mixing in modeling a stable boundary layer over Arctic sea ice. J. Geophys. Res. Atmos., 118, 1199-1217, https://doi.org/ 10.1002/JGRD.50158.

,,- T. Vihma, P. S. Anderson, F. C. Bosveld, and A. A. M. Holtslag, 2015: Clear-sky stable boundary layers with low winds over snow-covered surfaces. Part 1: WRF Model evaluation. Quart. J. Roy. Meteor. Soc., 141, 2165-2184, https:// doi.org/10.1002/QJ.2513.

Sun, J., and Coauthors, 2002: Intermittent turbulence associated with a density current passage in the stable boundary layer. Bound.-Layer Meteor., 105, 199-219, https://doi.org/10.1023/ A:1019969131774.

— , and Coauthors, 2004: Atmospheric disturbances that generate intermittent turbulence in nocturnal boundary layers. Bound.-Layer Meteor., 110, 255-279, https://doi.org/10.1023/ A:1026097926169.

_ L. Lahrt, R. M. Banta, and Y. L. Pichugina, 2012: Turbulence regimes and turbulence intermittency in the stable boundary layer during CASES-99. J. Atmos. Sci., 69, 338-351, https:// doi.org/10.1175/JAS-D-11-082.1.

,-- C. Nappo, and D. H. Lenschow, 2015: Wind and temperature oscillations generated by wave-turbulence interactions in the stably stratified boundary layer. J. Atmos. Sci., 72, 1484-1503, https://doi.org/10.1175/JAS-D-14-0129.1.

Svensson, G., and A. A. M. Holtslag, 2009: Analysis of model results for the turning of the wind and related momentum fluxes in the stable boundary layer. Bound.-Layer Meteor., 132, 261277, https://doi.org/10.1007/s10546-009-9395-1.

- - and Coauthors, 2011: Evaluation of the diurnal cycle in the atmospheric boundary layer over land as represented by a variety of single-column models: The second GABLS experiment. Bound.-Layer Meteor., 140, 177-206, https://doi.org/ 10.1007/S10546-011-9611-7.

Tastula, E.-M., T. Vihma, and E. L. Andreas, 2012: Evaluation of polar WRF from modeling the atmospheric boundary layer over Antarctic sea ice in autumn and winter. Mon. Wea. Rev., 140, 3919-3935, https://doi.org/10.1175/MWR-D-12-00016.1.

van der Linden, S. J. A., P. Baas, J. A. van Hooft, I. G. S. van Hooijdonk, F. C. Bosveld, and B. J. H. van de Wiel, 2017: Local characteristics of the nocturnal boundary layer in response to external pressure forcing. J. Appl. Meteor.
Climatol., 56, 3035-3047, https://doi.org/10.1175/JAMC-D-170011.1.

van de Wiel, B. J. H., R. J. Ronda, A. F. Moene, H. A. R. De Bruin, and A. A. M. Holtslag, 2002: Intermittent turbulence and oscillations in the stable boundary layer over land. Part I: A bulk model. J. Atmos. Sci., 59, 942-958, https://doi.org/10.1175/ 1520-0469(2002)059<0942:ITAOIT >2.0.CO;2.

—, A. F. Moene, G. J. Steeneveld, O. K. Hartogensis, and A. A. M. Holtslag, 2007: Predicting the collapse of turbulence in stably stratified boundary layers. Flow Turbul. Combust., 79, 251-274, https://doi.org/10.1007/s10494-007-9094-2.

,--1, and H. J. J. Jonker, 2012a: The cessation of continuous turbulence as precursor of the very stable nocturnal boundary layer. J. Atmos. Sci., 69, 3097-3127, https://doi.org/10.1175/ JAS-D-12-064.1.

,,,--- P. Baas, S. Basu, J. M. M. Donda, J. Sun, and A. A. M. Holtslag, 2012b: The minimum wind speed for sustainable turbulence in the nocturnal boundary layer. J. Atmos. Sci., 69, 3116-3127, https://doi.org/10.1175/JAS-D-12-0107.1.

— temperature inversions: A conceptual model. J. Atmos. Sci., 74, 1057-1073, https://doi.org/10.1175/JAS-D-16-0180.1.

van Hooijdonk, I. G. S., J. M. M. Donda, H. J. H. Clercx, F. C. Bosveld, and B. J. H. van de Wiel, 2015: Shear capacity as prognostic for nocturnal boundary layer regimes. J. Atmos. Sci., 72, 1518-1532, https://doi.org/10.1175/JAS-D-14-0140.1.

Van Ulden, A. P., and J. Wieringa, 1996: Atmospheric boundary layer research at Cabauw. Bound.-Layer Meteor., 78, 39-69, https://doi.org/10.1007/BF00122486.

Vercauteren, N., and R. Klein, 2015: A clustering method to characterize intermittent bursts of turbulence and interaction with submesomotions in the stable boundary layer. J. Atmos. Sci., 72, 1504-1517, https://doi.org/10.1175/JAS-D-14-0115.1.

Vignon, E., C. Genthon, H. Barral, C. Amory, G. Picard, H. Gallée, G. Casasanta, and S. Argentini, 2017a: Momentum- and heatflux parametrization at Dome C, Antarctica: A sensitivity study. Bound.-Layer Meteor., 162, 341-367, https://doi.org/ 10.1007/s10546-016-0192-3.

— Dome C, Antarctica: Observation and analysis. Quart. J. Roy. Meteor. Soc., 143, 1241-1253, https://doi.org/10.1002/qj.2998.

Walsh, J. E., W. L. Chapman, V. Romanovsky, J. H. Christensen, and M. Stendel, 2008: Global climate model performance over Alaska and Greenland. J. Climate, 21, 6156-6174, https:// doi.org/10.1175/2008JCLI2163.1.

Wenzel, A., N. Kalthoff, and V. Horlacher, 1997: On the profiles of wind velocity in the roughness sublayer above a coniferous forest. Bound.-Layer Meteor., 84, 219-230, https://doi.org/ 10.1023/A:1000444911103.

Westerhellweg, A., and T. Neumann, 2012: FINO1 mast correction. DEWI Mag., 40, 60-66.

Williams, A. G., S. Chambers, and A. Griffiths, 2013: Bulk mixing and decoupling of the nocturnal stable boundary layer characterized using a ubiquitous natural tracer. Bound.-Layer Meteor., 149, 381-402, https://doi.org/10.1007/ s10546-013-9849-3.

Zilitinkevich, S. S., T. Elperin, N. Kleeorin, I. Rogachevskii, I. Esau, T. Mauritsen, and M. W. Miles, 2008: Turbulence energetics in stably stratified geophysical flows: Strong and weak mixing regimes. Quart. J. Roy. Meteor. Soc., 134, 793-799, https://doi.org/10.1002/qj.264. 